\title{
Aerosol indirect effects from shipping emissions: sensitivity studies with the global aerosol-climate model ECHAM-HAM
}

\author{
K. Peters ${ }^{1,2, *}$, P. Stier ${ }^{3}$, J. Quaas ${ }^{4}$, and H. Graßl ${ }^{1}$ \\ ${ }^{1}$ Max Planck Institute for Meteorology, Hamburg, Germany \\ ${ }^{2}$ International Max Planck Research School on Earth System Modelling, Hamburg, Germany \\ ${ }^{3}$ Department of Physics, University of Oxford, UK \\ ${ }^{4}$ Institute for Meteorology, University of Leipzig, Leipzig, Germany \\ *now at: Monash University, School of Mathematical Sciences, Clayton, VIC 3800, Australia
}

Correspondence to: K. Peters (karsten.peters@monash.edu)

Received: 23 February 2012 - Published in Atmos. Chem. Phys. Discuss.: 8 March 2012

Revised: 12 June 2012 - Accepted: 20 June 2012 - Published: 13 July 2012

\begin{abstract}
In this study, we employ the global aerosol-climate model ECHAM-HAM to globally assess aerosol indirect effects (AIEs) resulting from shipping emissions of aerosols and aerosol precursor gases. We implement shipping emissions of sulphur dioxide $\left(\mathrm{SO}_{2}\right)$, black carbon $(\mathrm{BC})$ and particulate organic matter (POM) for the year 2000 into the model and quantify the model's sensitivity towards uncertainties associated with the emission parameterisation as well as with the shipping emissions themselves. Sensitivity experiments are designed to investigate (i) the uncertainty in the size distribution of emitted particles, (ii) the uncertainty associated with the total amount of emissions, and (iii) the impact of reducing carbonaceous emissions from ships.

We use the results from one sensitivity experiment for a detailed discussion of shipping-induced changes in the global aerosol system as well as the resulting impact on cloud properties. From all sensitivity experiments, we find AIEs from shipping emissions to range from $-0.32 \pm 0.01 \mathrm{~W} \mathrm{~m}^{-2}$ to $-0.07 \pm 0.01 \mathrm{~W} \mathrm{~m}^{-2}$ (global mean value and inter-annual variability as a standard deviation). The magnitude of the AIEs depends much more on the assumed emission size distribution and subsequent aerosol microphysical interactions than on the magnitude of the emissions themselves. It is important to note that although the strongest estimate of AIEs from shipping emissions in this study is relatively large, still much larger estimates have been reported in the literature before on the basis of modelling studies. We find that omitting just carbonaceous particle emissions from ships favours new particle formation in the boundary layer. These newly formed
\end{abstract}

particles contribute just about as much to the $\mathrm{CCN}$ budget as the carbonaceous particles would, leaving the globally averaged AIEs nearly unaltered compared to a simulation including carbonaceous particle emissions from ships.

\section{Introduction}

Ship tracks are widely seen as one of the most prominent manifestations of anthropogenic aerosol indirect effects (AIEs), or the change in cloud properties by anthropogenic aerosols serving as cloud condensation nuclei. A very uncertain and scientifically interesting question, however, is about the climatically relevant large-scale forcing by AIEs due to ship emissions.

In the past decades, a whole suite of AIE-hypotheses has been put forward of which the "Twomey-effect", or first AIE, is the most prominent. For this effect, an increase in available cloud condensation nuclei $(\mathrm{CCN})$ eventually leads to more and smaller cloud droplets if the liquid water content of the respective cloud remains constant. More cloud droplets increase the total droplet surface area by which the cloud albedo is enhanced; an effect which was put into the general context of anthropogenic pollution by Twomey (1974). Other AIE-hypotheses include effects on cloud lifetime (Albrecht, 1989; Small et al., 2009) or cloud top height (Koren et al., 2005; Devasthale et al., 2005). Especially the latter hypotheses are far from being verified (e.g. Stevens and Feingold, 2009). In total, AIEs are subject to the largest uncertainties 
of all radiative forcing (RF) components of the Earth System, when it comes to assessing human induced climate change (Forster et al., 2007). However, there exists broad consensus that on global average, AIEs have a cooling effect on the Earth System with the most recent multi-model estimate being $-0.7 \pm 0.5 \mathrm{~W} \mathrm{~m}^{-2}$ (Quaas et al., 2009).

Aerosols and aerosol precursor gases also lead to aerosol direct radiative effects (DREs), i.e. the aerosol particles absorb and scatter the incident solar radiation directly (Ångström, 1962). While regionally, a warming effect by aerosol absorption can be substantial (e.g. Peters et al., 2011a), globally, aerosol-DREs are believed to exert a net radiative cooling of about $-0.3 \pm 0.2 \mathrm{~W} \mathrm{~m}^{-2}$ on the Earth System (Myhre, 2009). In the recent climate-change discussion, the mitigation of carbonaceous emissions has attracted substantial attention in the scientific community. BC aerosols are associated with a net positive radiative forcing (RF) at the top-of-atmosphere (TOA) due to their strong absorption of incident solar radiation, also leading to semi-direct effects on cloud cover (Koch and Del Genio, 2010). Thus, BC is perhaps the fourth largest contributor to positive RF, following $\mathrm{CO}_{2}$, methane and tropospheric ozone and reducing its emission could contribute to delaying global warming due to anthropogenic climate change (e.g. Bond, 2007). However, this neglects the ability of $\mathrm{BC}$ particles to act as cloud condensation nuclei (CCNs) when they internally mix with hygroscopic species through microphysical and chemical ageing. This possibly leads to an overestimation of the cooling potential of BC mitigation options (e.g. Pierce et al., 2007; Spracklen et al., 2011).

Shipping is the most cost-effective mean of long distance cargo transportation (e.g. Borken-Kleefeld et al., 2010) and global ship traffic is expected to increase due to increasing international trade (e.g. Eyring et al., 2005a). Because greenhouse gas emissions from seagoing ships are not included in the Kyoto Protocol (1997), seagoing ships are one of the least regulated sources of anthropogenic emissions. It is estimated that in 2007, seagoing ships had a share of $2.7 \%$ in all anthropogenic $\mathrm{CO}_{2}$ emissions (Buhaug et al., 2009). Other gaseous emissions from ships include large amounts of nitrious oxides $\left(\mathrm{NO}_{\mathrm{x}}\right)$, methane and non-methane hydrocarbons. Furthermore, combustion of low-quality fuel, as used in ship engines, produces large amounts of aerosols and aerosol precursors. These come in form of particulate matter consisting of elemental (black) and organic carbon, ash and particles forming from sulfuric acid (e.g. Eyring et al., 2005b; Petzold et al., 2008). These constituents, being emitted in mostly pristine marine environments, can serve as cloud condensation nuclei (CCN) (e.g. Petzold et al., 2008) and result in AIEs.

AIEs from shipping emissions are occasionally manifested in linear cloud structures referred to as "ship tracks". These form as a result from ship effluents providing additional CCN which can potentially alter the micro- and macrophysical properties of maritime liquid-water clouds. Ship-tracks have been characterised in detail by a number of studies (see Peters et al., 2011b, and references therein). Those studies all focus on the detection and characterisation of ship tracks on local scales. The globally averaged RF of just ship tracks has been estimated to range from -8.9 to $-0.4 \mathrm{~m} \mathrm{~W} \mathrm{~m}^{-2}$ (Schreier et al. (2007) and A. Sayer, personal communication, 2011).

From a climate point of view however, it is important to get an impression of the large-scale RF resulting from shipping emissions. Apart from leading to ship-tracks, shipping emissions also have the potential to change the micro- and macrophysical properties of cloud fields also at a large, climatically relevant, scale. This is especially true for areas with widespread shipping emissions such as in the northern Atlantic and Pacific Oceans. Two observational studies have so far attempted to quantify such large scale effects from shipping emissions. While Devasthale et al. (2006) found evidence of cloud-property modification from shipping emissions over European coastal waters, Peters et al. (2011b) could not identify significant changes of cloud properties downwind of shipping routes over tropical oceans.

The above studies nicely illustrate the difficulty of establishing sound cause-and-effect relationships from observations. However, atmospheric modelling allows to explicitly separate the impact of shipping from the natural background. In recent years, modelling the impact of shipping emissions on the Earth System on climate relevant scales has received increasing attention. Most of these modelling studies focus on changes related to atmospheric chemistry and composition (Eyring et al., 2010, and references therein) and assessing global AIEs from shipping emissions has to date just been performed with two distinct models.

Capaldo et al. (1999) used shipping emissions of sulphur and organic material as presented in Corbett et al. (1999) in a global chemical transport model. The derived changes in atmospheric composition were then used to perform offline calculations of changes in $\mathrm{CCN}$ and the resulting RF. Their sensitivity tests, performed by varying input parameters like the background $\mathrm{CCN}$ concentration or the $\mathrm{CCN}$ cut-off radius, revealed RF values ranging from -0.21 to $-0.06 \mathrm{~W} \mathrm{~m}^{-2}$. Lauer et al. (2007) used three different shipping emission inventories and estimated globally averaged AIEs to range from -0.19 to $-0.60 \mathrm{~W} \mathrm{~m}^{-2}$. Their results highlight the importance of using an adequate geographical distribution of the shipping emissions, i.e. spread-out about shipping corridors rather than concentrated along main shipping routes. Lauer et al. (2009) tested the impact of future regulations regarding the sulfur content of marine bunker fuel (IMO, 1998). In their simulations, a reduction of the globally averaged fuel sulfur content from $2.7 \%$ (in 2002) to $0.5 \%$ (in 2012) lead to a reduction of globally averaged AIEs from shipping emissions from about -0.43 to about $-0.27 \mathrm{~W} \mathrm{~m}^{-2}$ despite an annual growth rate of fuel consumption of $4.1 \%$. Applying a model environment completely identical to Lauer et al. (2007) and Lauer et al. (2009), Righi et al. (2011) found 
the shipping emission induced AIE to range from -0.40 to $-0.28 \mathrm{~W} \mathrm{~m}^{-2}-$ despite the total assumed fuel consumption, and thus emissions, being higher than in Lauer et al. (2007). Righi et al. (2011) attribute this difference in obtained AIE to the use of a different geographical distribution of the shipping emissions. The DRE resulting from shipping emissions is small and estimated to range from -47.5 to $-9.1 \mathrm{~m} \mathrm{~W} \mathrm{~m}^{-2}$ (Balkanski et al., 2010; Eyring et al., 2010).

As the present estimate of the total greenhouse gas (GHG) $\mathrm{RF}$, as given by the IPCC, is about $+3 \mathrm{~W} \mathrm{~m}^{-2}$ (Forster et al., 2007), the above mentioned model results suggest that AIEs and DREs from shipping might mask a significant portion of the GHG induced radiative forcing. This masking may be reduced due to shipping emission regulations (e.g. Lauer et al., 2009), but even without those policy regulations, the estimated current cooling effect of shipping emissions will switch to a long-term warming (e.g. Fuglestvedt et al., 2009). This is because the warming related to the ship-emitted $\mathrm{CO}_{2}$ acts on timescales on the order of centuries whereas the cooling of the sulphuric compounds acts on timescales of decades when taking changes in oceanic heat content into account. Furthermore, evidence suggests that combustion of cleaner ship fuel also leads to reduced emission of particulate BC (Lack and Corbett, 2012), thereby reducing its potential cooling and warming effects. We here present an initial investigation of the magnitude of these effects.

In this study, we employ the state of the art global aerosolclimate model ECHAM-HAM to provide (1) insight into ship-emission processing in the model, and (2) a range of estimates of AIEs from shipping emissions. We derive this range of estimates from a series of sensitivity experiments which are designed to investigate (i) the uncertainties related to the size distribution of emitted particles, (ii) the uncertainty associated with the total amount of emissions, and (iii) the impact of reducing carbonaceous emissions from ships. The model framework, the used shipping emissions inventory and the experimental setup are described in Sect. 2. A detailed view of ship-emission processing in ECHAM-HAM is given in Sect. 3 and the results of the sensitivity experiments are presented in Sect. 4. Summary and conclusions are given in Sect. 5.

\section{Model and experiment setup}

Here, we utilise the global aerosol-climate model ECHAMHAM (Zhang et al., 2012) to thoroughly investigate the effect of shipping emissions on clouds. In the simulations discussed here, cloud cover is computed following a relative humidity-based approach (Sundqvist et al., 1989) and the treatment of convective clouds and -transport is based on the mass-flux scheme of Tiedtke (1989) with modifications for penetrative deep-convection according to Nordeng (1994). Gehlot and Quaas (2012) and Nam and Quaas (2012), using satellite observations, evaluated the ECHAM-simulated cloud cover using the same convection parameterisation but a different cloud cover scheme, i.e. that of Tompkins (2002). Both studies revealed that this model configuration overestimates high-cloud cover at the expense of mid- and lowlevel cloud cover, especially in the tropics and subtropics. As the ECHAM-simulated cloud fields are similar for both cloud-cover schemes (Quaas, 2012), these findings also hold for the model configuration we use in this study. As shipping emissions are most probably bound to impact the properties of low-level clouds, the AIEs obtained with this model may represent a low estimate, especially for tropical and subtropical regions. In addition, mesoscale dynamical features, such as the transition from open-cell to closed-cell stratocumulus clouds (e.g. Wang and Feingold, 2009; Sandu et al., 2010) cannot be represented in current global modelling approaches.

Cloud microphysics are computed according to Lohmann et al. (2007) some details of which are described below. Transport of physical quantities in gridpoint-space, such as water vapour, cloud water and -ice, and trace components is performed via a semi-lagrangian transport scheme (Lin and Rood, 1996). Here, ECHAM-HAM is used in nudged mode to relax the prognostic variables (vorticity, divergence, temperature and surface pressure) towards an atmospheric reference state (ERA-Interim reanalysis data; Simmons et al., 2007). A possible feedback of changes in cloud properties on the general circulation cannot be obtained from this kind of simulation. However, nudged simulations are the tool of choice in this study (as for many other AIE studies too) because this allows for the derivation of statistically significant results from relatively short simulations (i.e. five years in this case). Furthermore, Lohmann et al. (2010) have shown that AIEs obtained from short nudged simulations compare very well with those obtained from "free" simulations.

\subsection{Aerosol treatment}

ECHAM is coupled to HAM, a microphysical aerosol module which calculates the evolution of an aerosol population represented by seven interacting internally and externally mixed log-normal aerosol modes (Zhang et al., 2012). In the setup applied here, HAM treats sulfate (SU), black carbon (BC), particulate organic matter (POM), sea salt (SS) and dust (DU) aerosol. The modes consist of compounds with either low or no solubility (insoluble modes) or an internal mixture of insoluble and soluble compounds (soluble modes). The microphysical interaction among the modes, such as coagulation, condensation of sulfuric acid on the aerosol surface, and water uptake are calculated by the microphysical core M7 (Vignati et al., 2004). New particle formation is calculated as in the experiments of Kazil et al. (2010): specifically, neutral and charged nucleation (Kazil and Lovejoy, 2007) are used throughout the troposphere whereas activation nucleation (Kulmala et al., 2006) is limited to the forested boundary layer. Further, HAM treats 
emissions, sulfur chemistry (Feichter et al., 1996), dry and wet deposition and sedimentation and is coupled to radiative processes. The version of HAM used in this study is based on the original model presented in Stier et al. (2005) with several new developments. In their recent work, Zhang et al. (2012) present the changes applied to the original model version and evaluate these changes with respect to observations. Here, we will not delve into the details of this model evaluation, but it should be stated that the model-simulated aerosol size distribution and spatio-temporal variance of the aerosol population have improved compared to observations. Remaining deficiencies include positive and negative AOD biases over storm-tracks and high-latitudes, respectively, as well as a negative bias in particle number concentrations in the lower troposphere over polluted areas (Zhang et al., 2012).

\subsection{Cloud microphysics}

Here, cloud microphysical properties are derived using a double-moment scheme which solves prognostic equations for cloud water and -ice mass mixing ratios as well as for the number of cloud droplets and -ice crystals Lohmann et al. (2007). The parametrised microphysical processes relevant for liquid-water cloud properties are nucleation of cloud droplets, condensational growth of cloud droplets, autoconversion of cloud droplets to form rain water, accretion of cloud droplets by snow and by rain, and melting of cloud ice and snow. The amount of cloud liquid water mixing ratio, $q_{1}$, inside a grid box is provided by the condensation scheme (Sundqvist et al., 1989) with an additional source from convective detrainment, and is a prerequisite for performing the calculations of cloud microphysics.

The cloud microphysical scheme is coupled to HAM so that changes in the aerosol- and cloud population can feed back onto each other. Cloud droplet nucleation is parametrised as an empirical function of aerosol number concentrations (Lohmann et al., 2007) and Köhler theory based $\mathrm{CCN}$ diagnostics are also included. Autoconversion, i.e. conversion from cloud droplets to form precipitation, is treated according to Khairoutdinov and Kogan (2000), an empirical relationship where autoconversion negatively correlates with the number of cloud droplets. Thereby, cloud lifetime effects are explicitly included in the model. It is thus likely that the model overestimates the "cloud lifetime effect" (Quaas et al., 2009).

In ECHAM, the convection parametrisation provides for vertical transport and horizontal detrainment of cloud water and $\mathrm{CCN}$. The detrained $\mathrm{CCN}$ then serve as potential nuclei for stratiform clouds which form at the detrainment level. Convective clouds therefore only have an indirect effect on radiation through detrainment of liquid water to the stratiform scheme, i.e. they are assigned a cloud cover of zero.

\subsection{Aerosol-emission setup}

The emissions of dust (Tegen et al., 2002), sea salt (Guelle et al., 2001) and dimethyl sulfide (DMS, Kettle and Andreae, 2000) are computed on-line. The emissions of carbonaceous and sulfuric compounds, except those from shipping, are prescribed according to the AeroCom (Kinne et al., 2006) recommendations (for the year 2000, Dentener et al., 2006). Gaseous species (e.g. $\mathrm{OH}, \mathrm{NO}_{\mathrm{x}}$, ozone) are prescribed as monthly values after Horowitz et al. (2003).

We substitute the AeroCom shipping emissions (EDGAR, Bond et al., 2004; Olivier et al., 2005) with a dataset produced within the European Integrated Project QUANTIFY (EU-IP QUANTIFY) which comprises globally gridded data of shipping emissions for the year 2000 (Behrens, 2006).

In the QUANTIFY inventory, the geographical distribution of shipping emissions is performed by using a combination of COADS (Comprehensive Ocean-Atmosphere Data Set) and AMVER (Automatic Mutual-Assistance Vessel Rescue System) ship-traffic densities for the years 2000 and 2001/2002, respectively. To distribute the annual emissions in the QUANTIFY inventory, about 1000000 marine reports were used as input in both the COADS and AMVER datasets for deriving global ship reporting frequencies as illustrated in Endresen et al. (2003). The global distributions are shown in Dalsøren et al. (2009).

In addition to the uncertainties related to the geographical distribution of the shipping emissions, there also exist inherent uncertainties in the total fuel consumption of seagoing ships. In the QUANTIFY inventory, the total annual fuel consumption is estimated at $172.5 \mathrm{Mt}$ of total fuel consumption for the year 2000 which is substantially lower than the estimates of Corbett and Koehler (2003) and Eyring et al. (2005b), being $289 \mathrm{Mt}$ and $280 \mathrm{Mt}$, respectively. The large differences between QUANTIFY and the other inventories concerning the fuel consumption estimates have been a matter of intense debate and it has been shown that the assumed level of activity (or "days at sea") is the main reason for the large differences (e.g., Endresen et al., 2004; Corbett and Koehler, 2004). The spatially gridded QUANTIFY inventory we use in this study does not include emissions in ports. Fuel consumption in ports is estimated at $11.6 \mathrm{Mt}$ for the year 2000, thereby representing about $6.3 \%$ of total fuel consumption (Behrens, 2006).

We apply the emissions as a constant flux (in $\left[\mathrm{kg} \mathrm{m}^{-2} \mathrm{~s}^{-1}\right]$ ) of annually averaged data to the model layer above the surface layer. We acknowledge that applying the emissions in such a way leads to dilution of the emissions, thereby neglecting sub-grid processes of emission processing in the atmosphere (i.e. Stevens et al., 2012). The possibility of employing effective emissions (Paoli et al., 2011), i.e. emissions modified to represent the effect of unresolved processes on the scale of a GCM grid-box, was previously explored by Franke et al. (2008). In that study, the authors found substantial effects on ozone chemistry, but neither 
did they discuss possible implications for AIEs nor was the method applied to a full GCM. More recently, Huszar et al. (2010) employed an exhaust plume parameterisation for shipping emissions on a regional scale (Eastern Atlantic and Western Europe) using a model environment encompassing a regional climate model and a chemical transport model. Similar to Franke et al. (2008), they found substantial effects on atmospheric chemistry, mainly comprising reduced abundance of $\mathrm{NO}_{\mathrm{x}}$ and ozone over main shipping corridors compared to a simulation utilising the standard emission implementation of instantaneous dilution. Although these results are stimulating, including sub-grid scale effects on emission processing is well beyond the scope of this study and we therefore stick to the conventional method of instantly diluting the shipping emissions to a GCM grid-box. Monthly resolved ship traffic density datasets on the basis of AMVER and COADS data do exist (e.g. Wang et al., 2007; Lamarque et al., 2010), but the uncertainty introduced by using annually mean emission fields is probably negligible compared to the uncertainty associated with the emissions themselves (A. Lauer, personal communication, 2011).

\subsection{Experimental setup}

To quantify the effect of shipping emissions on clouds, we perform and analyse a total of seven GCM experiments. The experiments are designed to highlight the uncertainties associated with the total global annual fuel consumption and the emission size distribution as well as to investigate the potential and implications of mitigating carbonaceous-particle emissions from ships. Simulations are performed with a horizontal resolution of $\mathrm{T} 63$ (about $1.8 \times 1.8^{\circ}$ ) and a vertical resolution of 31 levels up to $10 \mathrm{hPa}$. Monthly mean sea surface temperatures and sea ice cover are prescribed according to the AMIP II dataset (Atmospheric Model Intercomparison Project; Taylor et al., 2000). The performed simulations span the time period from October 1999 to December 2004. The first three months are considered as model spin-up and the analysis is then performed on the remaining five years.

For our reference simulation CTRL, we run the model with the emissions prescribed for the AeroCom setup (Dentener et al., 2006) excluding all shipping emissions. This simulation thus yields the base case scenario for estimating the AIEs from shipping emissions as computed from the sensitivity experiments described below.

In experiment $\mathrm{A}$, we run the model with the QUANTIFY inventory using the originally implemented shipping emissions parametrisation (AeroCom, "old" in Table 1). We slightly modify the original emission parametrisation because we found it to be inconsistent - the carbonaceous compounds from shipping emissions were originally assigned to the model's surface layer whereas the sulphuric compounds where assigned to one layer above the model's surface layer. This is because shipping emissions are considered as part of industrial emissions in AeroCom. For industrial emissions of sulphuric compounds, an emission height well above the surface is assumed because industrial plants emit most of their exhausts from smoke stacks. This method is not applied to industrial carbonaceous emissions because their fraction in the stack-emissions is assumed to be negligible (S. Kinne, personal communication, 2010). We therefore modify the emission routine in HAM so that all emissions from ships are consistently assigned to the model layer above the surface layer. Over oceans, the model level above the surface level covers the air-volume from about $60-150 \mathrm{~m}$ for mid-latitudes and $65-170 \mathrm{~m}$ for the tropics.

In experiment $\mathrm{A}$, the emissions of $\mathrm{BC}$ and $\mathrm{POM}$ are assigned to the insoluble Aitken mode with a number mean radius of $\bar{r}=0.03 \mu \mathrm{m}$ and a standard deviation of the lognormal distribution of $\sigma=1.59$. The bulk of sulfuric emissions is emitted in form of gaseous $\mathrm{SO}_{2}$. Fast processing of gaseous $\mathrm{SO}_{2}$ emissions is accounted for by allowing a certain fraction $f_{\mathrm{SO}_{4}}$ of the emitted sulfuric mass to transform to particulate sulfate at the point of emission instantaneously (i.e., within one timestep). In the AeroCom setup as used in experiment $\mathrm{A}, f_{\mathrm{SO}_{4}}=2.5 \%$. Of this particulate sulfate, $50 \%$ is assigned to the soluble Accumulation mode (AS, $\bar{r}=0.075 \mu \mathrm{m}, \sigma=1.59)$ and $50 \%$ is assigned to the soluble Coarse mode (CS, $\bar{r}=0.75 \mu \mathrm{m}, \sigma=2$ ).

To investigate the uncertainty associated with the insufficient knowledge of the emission size distribution, we developed experiment B. A close look at the original emission parametrisation as used in A yields significant discrepancies to what is currently known about the microphysicaland chemical properties of shipping emissions.

First, recent studies indicate that the $f_{\mathrm{SO}_{4}}$ is often larger than $2.5 \%$. Agrawal et al. (2008) performed exhaust gas measurements inside a container-ships' stack and found a value of $f_{\mathrm{SO}_{4}}=3.7-5 \%$ (positively correlated with engine load) for a fuel sulphur content of $2.05 \%$. These results are confirmed by Agrawal et al. $(2010)\left(f_{\mathrm{SO}_{4}}=2.4-\right.$ $5 \%$ with fuel sulfur content of $3.01 \%$ ). Lack et al. (2009) measured ship-emission plume compositions within $15 \mathrm{~min}$ post-emission and deduced $f_{\mathrm{SO}_{4}}=1.4 \pm 1.1 \%$ and $f_{\mathrm{SO}_{4}}=$ $3.9 \pm 2.0 \%$ for low $(<0.5 \%)$ and high $(>0.5 \%)$ fuel sulphur content, respectively. The authors however do not give information on possible mechanisms behind the dependence of $f_{\mathrm{SO}_{4}}$ on the fuel sulfur content. Applying the current state of knowledge, we increase $f_{\mathrm{SO}_{4}}$ from $2.5 \%$ to $4.5 \%$ in experiment $\mathrm{B}$, being a realistic estimate considering that the model time step is on the order of the measurement timescale of Lack et al. (2009) and that the globally weighted marine fuel sulphur content is estimated at $2.68 \%$ for 2002 (Endresen et al., 2004).

Second, the assumed emission size distribution of primary sulfate particles may be too large in AeroCom (see above). A number of studies have shown that ships emit a suite of particles which are all in the size range $\bar{r}<0.05 \mu \mathrm{m}$. Specifically, Petzold et al. (2008) investigated the particle size distribution in an aged plume (20 min old, which is roughly on 
Table 1. Experimental setup configurations for the performed GCM runs. The "old" emission parameterisation refers to the operational AeroCom method whereas the "new" one was developed in this study. The acronyms for the emission modes are: KI (Aitken insoluble), KS (Aitken soluble), AS (Accumulation soluble), CS (Coarse soluble). $f_{\mathrm{SO}_{4}}$ denotes the mass fraction of emitted sulfur to be emitted as primary sulfate. HAM treats OC emissions as emissions of POM. OC emissions are therefore scaled by 1.4 to obtain values of emitted POM. The approximate number of emitted soluble particles $\mathrm{s}^{-1}$ is shown to illustrate the effect of the applied model changes.

\begin{tabular}{|c|c|c|c|c|c|c|}
\hline \multirow[b]{2}{*}{ Experiment } & \multirow[b]{2}{*}{$\begin{array}{l}\text { emiss. } \\
\text { par. }\end{array}$} & \multirow[b]{2}{*}{$\begin{array}{c}\text { shipping emissions } \\
\mathrm{SO}_{2}, \mathrm{BC}, \mathrm{OC}(\mathrm{POM})\left[\mathrm{Tg} \mathrm{yr}^{-1}\right]\end{array}$} & \multicolumn{3}{|c|}{ Particulate emissions, emission mode } & \multirow[b]{2}{*}{$\begin{array}{c}\approx \# \text { of emitted } \\
\text { sol. particles }\left[\mathrm{s}^{-1}\right]\end{array}$} \\
\hline & & & $f_{\mathrm{SO}_{4}}$ & $\mathrm{BC}$ & $\mathrm{OC}(\mathrm{POM})$ & \\
\hline CTRL & old & - & - & - & - & - \\
\hline A & old & $7.95,0.03,0.11$ & $\begin{array}{c}2.5 \% \\
(50 \% \mathrm{AS}, 50 \% \mathrm{CS})\end{array}$ & KI & KI & $4.8 \times 10^{17}$ \\
\hline B & new & $7.95,0.03,0.11$ & $4.5 \%, \mathrm{KS}$ & KS & KS & $8 \times 10^{19}$ \\
\hline Asc & old & $12.95,0.05,0.18$ & $\begin{array}{c}2.5 \% \\
(50 \% \mathrm{AS}, 50 \% \mathrm{CS})\end{array}$ & KI & KI & $7.8 \times 10^{17}$ \\
\hline Bsc & new & $12.95,0.05,0.18$ & $4.5 \%, \mathrm{KS}$ & KS & KS & $1.3 \times 10^{20}$ \\
\hline BnoBC & new & $7.95,-, 0.11$ & $4.5 \%, \mathrm{KS}$ & - & KS & $7.6 \times 10^{19}$ \\
\hline BnoC & new & $7.95,-,-$ & $4.5 \%, \mathrm{KS}$ & - & - & $5.5 \times 10^{19}$ \\
\hline
\end{tabular}

the order of the model timestep) of shipping emissions over the English Channel and found that the modal radius of the ship-emitted particles was $\approx 0.02-0.04 \mu \mathrm{m}$. Because this size range corresponds to that of the Aitken mode in HAM, we assign all ship-emitted primary sulfate particles to the soluble Aitken mode (modal radius: $0.03 \mu \mathrm{m}$ ) in experiment B. In a recent study, Righi et al. (2011) also investigated the effect of changing the size distribution of emitted particles from shipping emissions in a GCM environment and found that AIEs substantially depend on the assumed size distribution of emitted particles, i.e. emission of smaller and thus more particles for the same emitted mass yields substantially larger AIE-estimates.

Third, all carbonaceous particles from shipping emissions are assumed insoluble at the point of emission in the original AeroCom parametrisation. This assumption however is inconsistent with recent laboratory measurements. Kireeva et al. (2010) showed that freshly emitted soot from a ship engine burning fuel with a sulfur content of just $0.5 \%$ yields significantly higher solubility than soot emitted from an aircraft- or truck engine. Motivated by these results, we assign all ship-emitted carbonaceous particles to the soluble Aitken mode (modal radius: $0.03 \mu \mathrm{m}$ ) in experiment B, similar to Lauer et al. (2007) and one experiment in Righi et al. (2011). Therefore, the model setup for experiment B also yields a better comparison framework to earlier studies.

In the experiments Asc and Bsc, we scale the emissions of the QUANTIFY inventory in order to investigate the uncertainty associated with the unknown total annual fuel consumption from ships. As previously noted, the QUANTIFY inventory represents a lower estimate among the currently used shipping emission inventories. Therefore, the mass of annually emitted particulate- and gaseous species is scaled to values which meet the ones published by Corbett and Koehler (2003). There, the annual total emission of $\mathrm{SO}_{2}$ is given as $12.98 \mathrm{Tg}$ (based on ship activity for the year 2001). Relating this to the given value in the QUANTIFY inventory (7.95 Tg; year 2000), we scale the emissions of $\mathrm{SO}_{2}, \mathrm{BC}$ and POM by a factor of 1.63 for use in the experiments Asc and Bsc. In the study of Lauer et al. (2007), the highest annual total emission of $\mathrm{SO}_{2}$ was $11.7 \mathrm{Tg}$ and Righi et al. (2011) used maximum annual $\mathrm{SO}_{2}$ emissions of $14 \mathrm{Tg}$. This has to be kept in mind when interpreting the results.

In the experiments BnoBC and $\mathrm{BnoC}$, we explore the potential effects of mitigating the emission of carbonaceous compounds from ships. For both experiments, we employ the model with the newly introduced emission parametrisation (see experiment $\mathrm{B}$ ). We omit all $\mathrm{BC}$ and all carbonaceous emissions from ships in experiments BnoBC and BnoC, respectively. These simulations thus represent idealised sensitivity studies because no potential side-effects that BC mitigation may have on the magnitude of sulfuric emissions (and vice-versa, Lack and Corbett, 2012, and references therein) are included.

Although very intriguing, we explicitly do not attempt to assess the climate impact of emission controls resulting from a reduction of fuel sulfur content on local and global scales (IMO, 1998; Lauer et al., 2009; Righi et al., 2011) and this should thus be an important topic of future climate model intercomparison studies.

\section{Ship-emission induced aerosol processes in ECHAM-HAM}

To illustrate the pathway from shipping emissions to changes in the TOA radiation budget as modelled by ECHAM-HAM, 

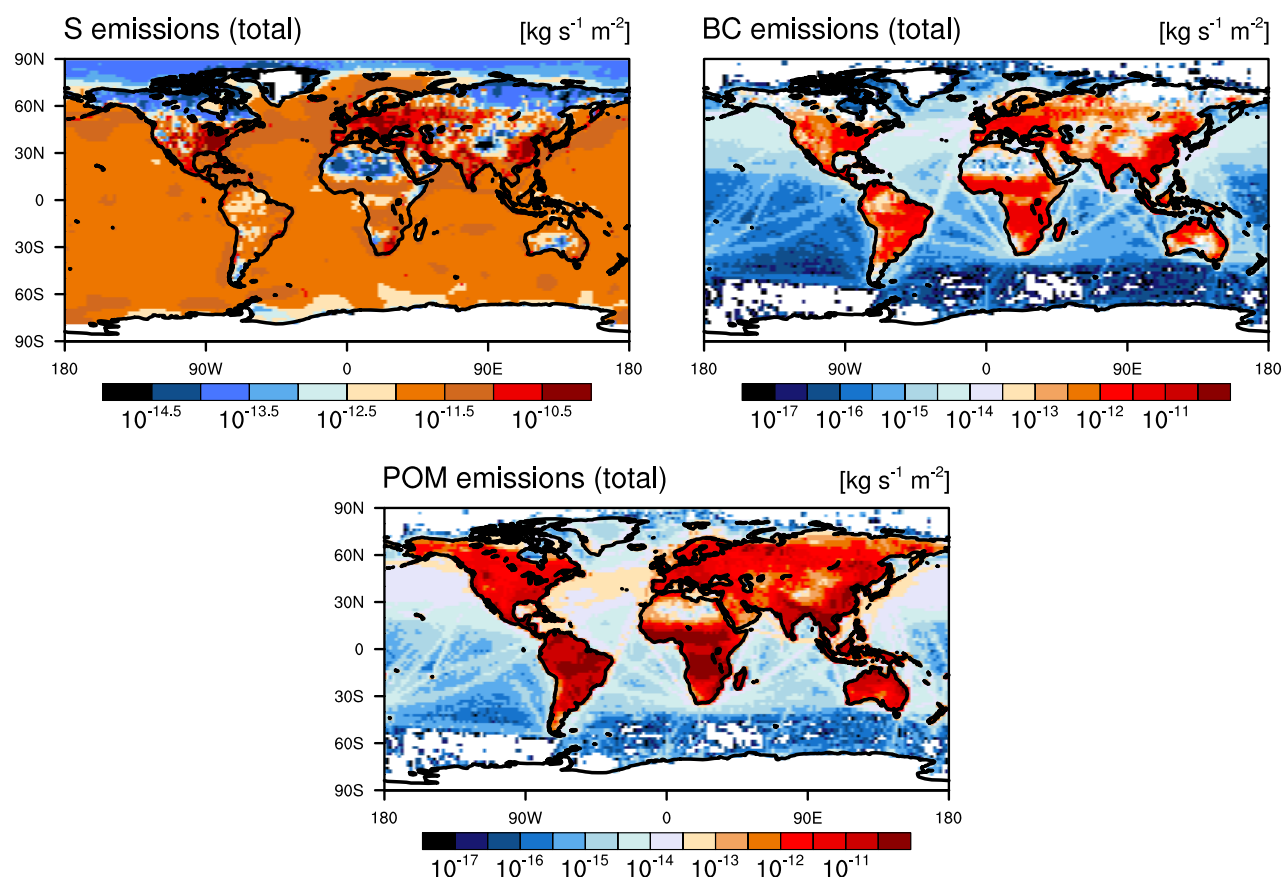

Fig. 1. Total emissions of aerosols and aerosol precursors as used in experiment setup B. Top left: sulphur (comprised of sulphur dioxide $\left(\mathrm{SO}_{2}\right)$, sulfate and DMS); top right: $\mathrm{BC}$; bottom: particulate organic matter (POM). The colour scales denote the $\log _{10}$ of emission fluxes in $\left[\mathrm{kg} \mathrm{s}^{-1} \mathrm{~m}^{-2}\right]$. Emissions over land correspond to those prescribed in AeroCom (Dentener et al., 2006), anthropogenic emissions over water surfaces to those provided in the QUANTIFY shipping emission inventory (Behrens, 2006).

we perform a stepwise analysis using the results obtained from experiment B. The steps in this analysis consider the changes in

- emissions,

- aerosol mass- and number burdens,

- CCN concentrations,

- cloud macro- and microphysical properties,

- radiation budget.

In the following, the displayed figures represent simulated five-year mean values. Statistical significance is computed by applying a two-tailed Student's t-test to the respective five annually averaged fields and the standard deviation of the five annual means in each grid-box. The level of statistical significance applied to all plots is $90 \%$, i.e. the null hypothesis (that the sample means are from the same population) is true with $<10 \%$ probability and is thereby rejected in the regions indicated by the contours in the plots.

\subsection{Changes in emissions and mass burdens}

The global distributions of total sulphur (comprised of sulphur dioxide $\left(\mathrm{SO}_{2}\right)$, sulfate and dimethyl sulphide (DMS)), black carbon $(\mathrm{BC})$ and particulate organic matter (POM) emissions as used in experiment B are shown in Fig. 1. Shipping emissions represent just a small fraction of the global mean anthropogenic emissions: $7.2 \%$ for $\mathrm{S}, 0.5 \%$ of $\mathrm{BC}$ and $0.25 \%$ of POM. However, emissions from shipping often occur in otherwise pristine marine environments and can therefore result in substantial modifications of the aerosol populations in the marine boundary layer.

As shown in Fig. 2, the relative changes in $\mathrm{SO}_{2}$ column burden are very similar to the spatial pattern of shipping emissions on global oceans. We obtain the largest changes over the Northern Hemisphere (NH) Atlantic Ocean, the northern Indian Ocean and the northern Pacific Ocean, with most changes being statistically significant at the $90 \%$ level. Relative changes in sulfate column burden show smaller values in Southeast Asia compared to the western European coast although the changes in $\mathrm{SO}_{2}$ column burden are of similar magnitudes. Because $\mathrm{SO}_{2}$ is oxidised to $\mathrm{H}_{2} \mathrm{SO}_{4}$ by $\mathrm{OH}$, this can be explained by higher $\mathrm{OH}$ abundance over the North Atlantic in the monthly prescribed fields (Horowitz et al., 2003). Also, aqueous oxidation in cloudy scenes is most probably higher over the North Atlantic compared to Southeast Asia due to higher cloud fractions in low- and midlevels (Nam, 2011).

The relative changes in atmospheric $\mathrm{BC}$ - and $\mathrm{OC}$ burdens only show distinct patterns over the northwestern Atlantic and none of these features is statistically significant at the $90 \%$ level. Therefore, it is plausible that the emissions of 

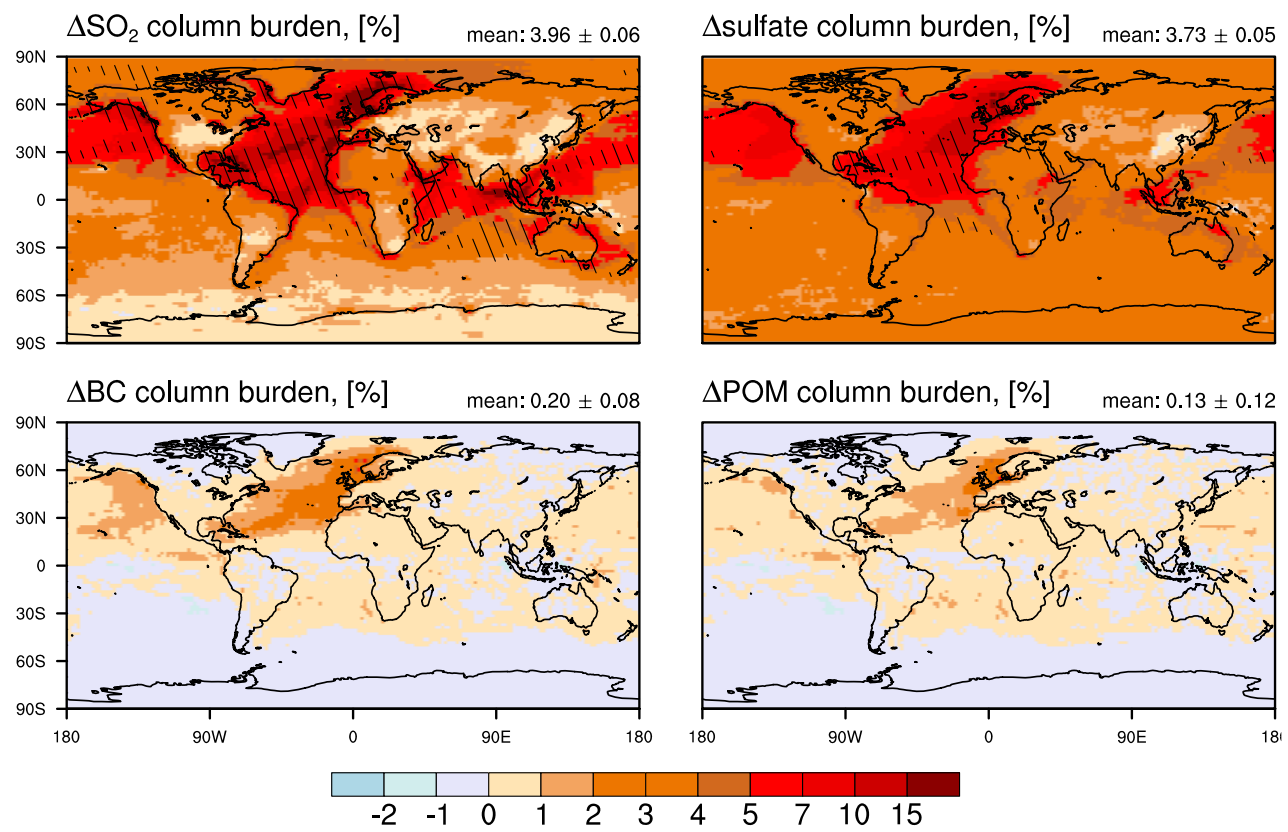

Fig. 2. Ship-emission induced five-year annual mean relative changes in [\%] of column burden of sulphur dioxide ( $\mathrm{SO}_{2}$, top left), sulfate (top right), black carbon (BC, bottom left) and particulate organic matter (POM, bottom right) in experiment $\mathrm{B}$ compared to experiment CTRL (derived from $\left.\left(\frac{\mathrm{B}-\mathrm{CTRL}}{\mathrm{CTRL}} \cdot 100\right)\right)$. Please note the non-linear contour spacing. Changes in diagonally-patterned areas are statistically significant at the $90 \%$ level.

sulfuric constituents from ships are the ones which ultimately determine the total effect on both cloudy- and clear sky radiation (e.g. Lauer et al., 2009).

\subsection{Changes in aerosol number}

It is feasible to track the models' response induced by a certain change in emission parameters through each aerosol mode, thereby clarifying the underlying processes leading to the observed total response. We order the analysis from the smallest to largest aerosol modes. We show the verticallyand meridionally resolved changes in particle number concentrations in Fig. 3.

Due to the increased availability of condensable material, i.e. sulphuric acid $\left(\mathrm{H}_{2} \mathrm{SO}_{4}\right)$, non-soluble particles are converted to soluble ones via condensation of $\mathrm{H}_{2} \mathrm{SO}_{4}$ onto them. This can clearly be depicted for the insoluble Aitken (KI), Accumulation (AI) and Coarse (CI) modes (top row Fig. 3).

The population of soluble Nucleation mode (NS) particles by design consists only of secondary aerosol resulting from new particle formation, mainly nucleated from sulfuric acid $\left(\mathrm{H}_{2} \mathrm{SO}_{4}\right)$. Vertically resolved, pronounced relative increases in NS-particle concentrations are constrained to the NH midand upper troposphere (Kazil et al., 2010) as well as some parts of tropical boundary layer (bottom row Fig. 3). Because these areas are relatively unpolluted, the lack of condensational sinks favours particle nucleation. However, a decrease in NS-particle numbers is obtained for the NH mid-latitude boundary layer and lower troposphere (up to $\approx 800 \mathrm{hPa}$ ). There, condensation of $\mathrm{H}_{2} \mathrm{SO}_{4}$ onto pre-existing particles substantially dominates over new particle formation.

Soluble Aitken mode (KS) particle number concentrations decrease in the NH boundary layer (bottom row Fig. 3). The cause for this is two-fold. Firstly, less nucleated NSparticles (see above) result in less particles growing to KS and secondly, the increased availability of condensable material $\left(\mathrm{H}_{2} \mathrm{SO}_{4}\right)$ leads to higher condensation rates onto the already present and additionally emitted KS particles. This yields faster growth rates to the soluble Accumulation mode (AS) and thus shorter residence time in KS. For the mid- and upper troposphere, the overall increase in KS-particle number concentrations results from growth of the increasingly present NS-particles (see above).

Particle number burdens in the soluble Accumulation mode (AS) increase everywhere on the globe. In relative terms, regions of largest increase correspond to those of highest shipping emissions in the North Atlantic, North Pacific, mid-Indian Ocean, and Southeast Asia (not shown). The vertically and meridionally resolved changes in ASparticle number concentrations show an increase practically everywhere throughout the troposphere (bottom row Fig. 3). Especially in the NH boundary layer, the condensational growth of the emitted KS-particles thus leads to a significant increase ("accumulation") of particles in AS. This is of particular interest as that size range is most suitable for 

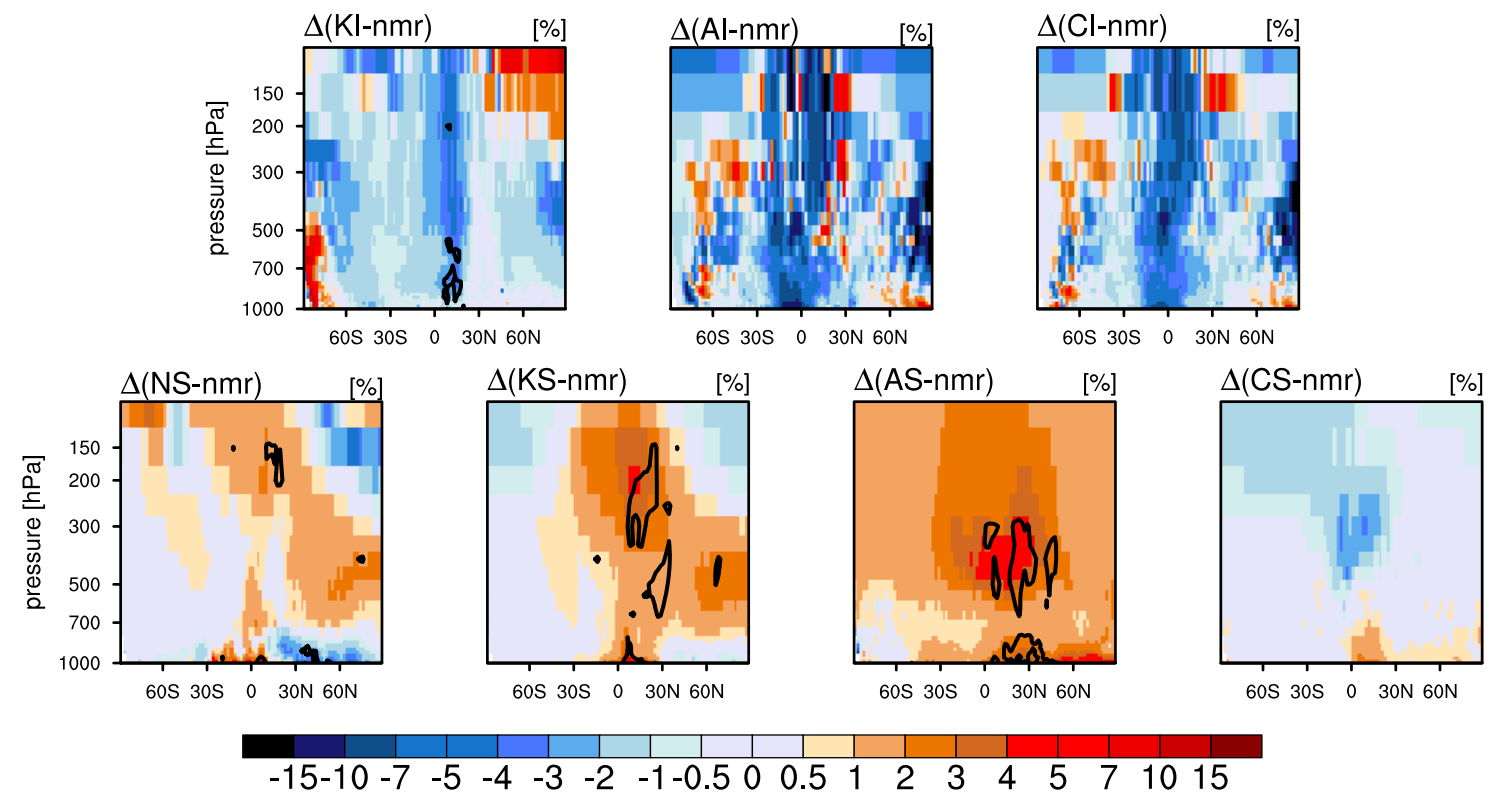

Fig. 3. Ship-emission induced five-year annual zonal mean relative changes in [\%] of particle number mixing ratios (nmr) in experiment B compared to experiment CTRL (derived from $\left.\left(\frac{\mathrm{B}-\mathrm{CTRL}}{\mathrm{CTRL}} \cdot 100\right)\right)$. The change of particle number concentration in each aerosol mode, as resolved by ECHAM-HAM, is shown. The acronyms in the plot captions denote the respective aerosol mode in HAM and are as follows: KI (aitKen Insoluble), AI (Accumulation Insoluble), CI (Coarse Insoluble), NS (Nucleation Soluble), KS (aitKen Soluble), AS (Accumulation Soluble), CS (Coarse Soluble). Please note the non-linear contour spacing. The black contour lines enclose areas showing statistical significance at the $90 \%$ level.

$\mathrm{CCN}$-activation at supersaturations typical for stratocumulus clouds ( $80-100 \mathrm{~nm}$ at $0.2 \%$ supersaturation, e.g. Pierce and Adams, 2009).

The increase in soluble Coarse mode (CS) particle concentrations is confined to the lower troposphere, but is not as large as for AS and is not statistically significant at any point in the troposphere.

To summarise, the introduction of shipping emissions leads to reduced particle nucleation and substantially increased condensational growth rates of primary Aitken-mode sized particles in the NH boundary layer. This results in decreased particle number concentrations in both NS and KS and increased AS-particle number concentrations in the NH boundary layer. Furthermore, the increased availability of sulfuric compounds leads to increased particle nucleation rates throughout the tropical troposphere, which results in increased particle number concentrations in all soluble modes but the Coarse mode.

Although most of the discussed changes in particle number concentrations occur outside the specified confidence intervals, we are confident that the shown plots and explanations represent the actual processing of shipping emissions to a high degree of accuracy. Running the model for an even longer time period would most probably increase the areas of significant changes. As this is however computationally quite expensive, performing such extra simulations is beyond the scope of this study.
The aforementioned faster growth rates of aerosol particles could in fact lead to a reduction of their atmospheric lifetimes due to enhanced wet deposition through cloud interaction. Aerosol lifetimes, defined here as the ratio of burdens over sources, are displayed in Table 2. Indeed, lifetimes are slightly reduced for all aerosol types in experiment $\mathrm{B}$, with the exception of sea salt.

The impact of the shipping emissions on the aerosol population and its direct effect on atmospheric radiation is illustrated by the relative changes in AOD and its fine mode component (i.e. the contribution from particles smaller than $1 \mu \mathrm{m}$ in diameter), as shown in Fig. 4. Statistically significant increases in both the AOD and its fine mode are obtained for most of the western European coastal waters as well as some areas off the western coast of North America. The globally averaged relative increase in the fine-mode AOD is larger than that obtained for the total AOD. This should be expected, as the main increase in particle numbers is found for Accumulation mode sized particles, which are by definition smaller than $1 \mu \mathrm{m}$ in diameter. The impact of this change in AOD on clear-sky atmospheric radiation will be discussed in Sect. 3.5.

\subsection{Changes in predicted $\mathrm{CCN}$ concentrations}

We show vertically- and meridionally resolved changes in CCN concentrations, derived from Köhler theory, at various 
Table 2. Atmospheric lifetimes of the aerosol species considered in ECHAM-HAM in experiment CTRL [days] and changes in the remaining experiments with respect to CTRL [minutes]. The lifetime is defined as the ratio of total burden over total sources. All aerosol species treated in ECHAM-HAM are considered here, i.e. sulfate, black carbon (BC), particulate organic matter (POM), sea salt (SS) and dust (DU).

\begin{tabular}{|c|c|c|c|c|c|c|c|}
\hline Compound & CTRL & A & B & Asc & Bsc & BnoBC & BnoC \\
\hline sulfate & $4.8 \pm 0.16$ & $-7.9 \pm 2.7$ & $-30.5 \pm 3.5$ & $-32.8 \pm 6.3$ & $-18.9 \pm 4.3$ & $-29.2 \pm 5.5$ & $0.3 \pm 1.9$ \\
\hline $\mathrm{BC}$ & $6.3 \pm 0.17$ & $-3.9 \pm 7.2$ & $-17.8 \pm 12.1$ & $-16 \pm 10.2$ & $-16.7 \pm 8.5$ & $-4 \pm 3.3$ & $10.2 \pm 13.2$ \\
\hline POM & $6.1 \pm 0.19$ & $-7.6 \pm 9.6$ & $-2.7 \pm 17$ & $-11.5 \pm 14.7$ & $-8.4 \pm 13.2$ & $-10.4 \pm 2.6$ & $-4.9 \pm 19.2$ \\
\hline SS & $0.7 \pm 0.006$ & $-1.6 \pm 0.1$ & $2.3 \pm 0.1$ & $-1.3 \pm 0.1$ & $0.9 \pm 0.1$ & $2.2 \pm 0.3$ & $-0.06 \pm 0.1$ \\
\hline DU & $4.9 \pm 0.2$ & $1.6 \pm 7.2$ & $-19 \pm 6.2$ & $-11.5 \pm 11.8$ & $-14.3 \pm 11.5$ & $-19 \pm 9$ & $2.3 \pm 8.9$ \\
\hline
\end{tabular}

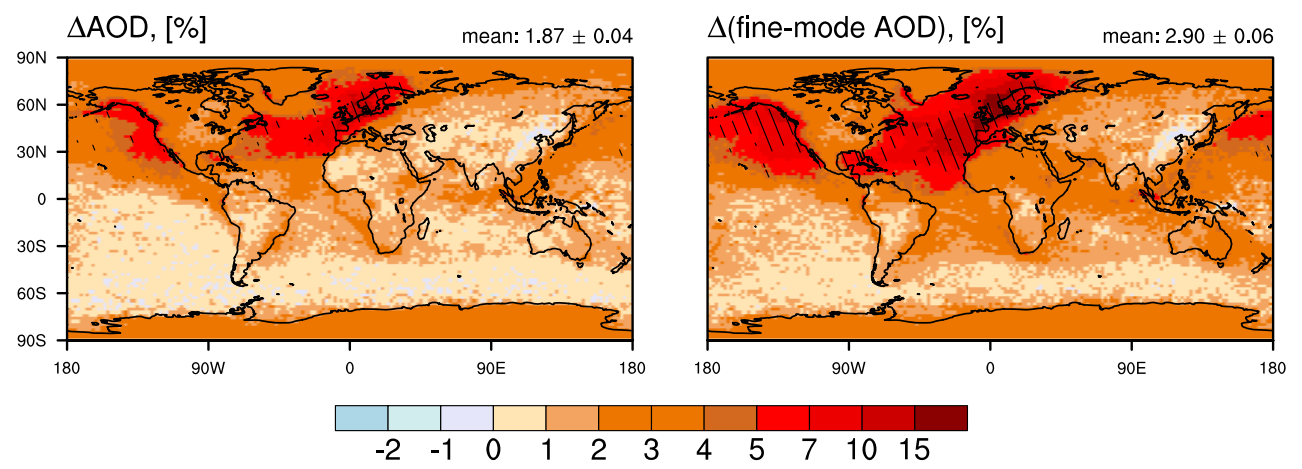

Fig. 4. Ship-emission induced five-year annual mean relative changes in [\%] of aerosol optical depth (AOD, left) and fine-mode AOD (right) in experiment B compared to experiment CTRL (derived from $\left.\left(\frac{\mathrm{B}-\mathrm{CTRL}}{\mathrm{CTRL}} \cdot 100\right)\right)$. Please note the non-linear contour spacing. Changes in diagonally-patterned areas are statistically significant at the $90 \%$ level.

supersaturations in Fig. 5. At low supersaturations (0.04\%), large areas in the $\mathrm{NH}$ lower- to mid troposphere exhibit a significant increase in $\mathrm{CCN}$ concentrations, with values $>10 \%$ occurring in the boundary layer north of $60^{\circ} \mathrm{N}$, closely following the changes in AS particle number. CCN concentrations at higher supersaturations show a similar pattern but an increasing contribution of $\mathrm{KS}$ number changes, in particular in the tropics. This again hints at aerosol processing in the boundary layer - smaller particles (higher supersaturations) are found near the emission sources whereas larger particles (smaller supersaturations) are found higher up in the troposphere as a result of microphysical- and chemical ageing during transport. Distinct and often statistically significant increases in $\mathrm{CCN}$ concentrations are also found for the mid to high tropical troposphere.

Summarising, it is evident that shipping emissions lead to an increased number of CCNs at supersaturations typical for marine liquid water clouds. This follows from distinct increases in AS particle numbers, especially in the NH boundary layer, as a result from increased particle growth rates (see Sect. 3.2).

\subsection{Changes in cloud micro- and macrophysical properties}

As shown in Fig. 6 (top left), distinct and sometimes significant increases of CDNC are calculated throughout the North Atlantic- and North Pacific Oceans as well as off the southwestern coast of Africa. Close to the coasts of northwestern Europe and California, CDNCs are increased by more than $15 \%$. The changes over tropical oceans are rather noisy because here, the relatively large variations in macrophysical cloud properties, such as cloud liquid water path/geometrical thickness, dominate the signal even for the five year averages considered here. This is in-line with the findings of Peters et al. (2011b) and a more thorough comparison to observations will be performed in the future.

Vertically resolved (Fig. 6, top right), we find distinct and often statistically significant changes in CDNC throughout the mid-latitude $\mathrm{NH}$ troposphere up to $\approx 400 \mathrm{hPa}$. Correspondingly, $r_{\text {eff }}$ decreases, often statistically significant, throughout the mid-latitude Pacific and Atlantic Oceans as well as off the western coast of southern Africa (Fig. 6, bottom left).

Via the parametrisation of the autoconversion (i.e. the conversion of cloud- to precipitation water after Khairoutdinov and Kogan, 2000), a response of cloud macrophysical properties to changes in CDNC is incorporated in the model. 

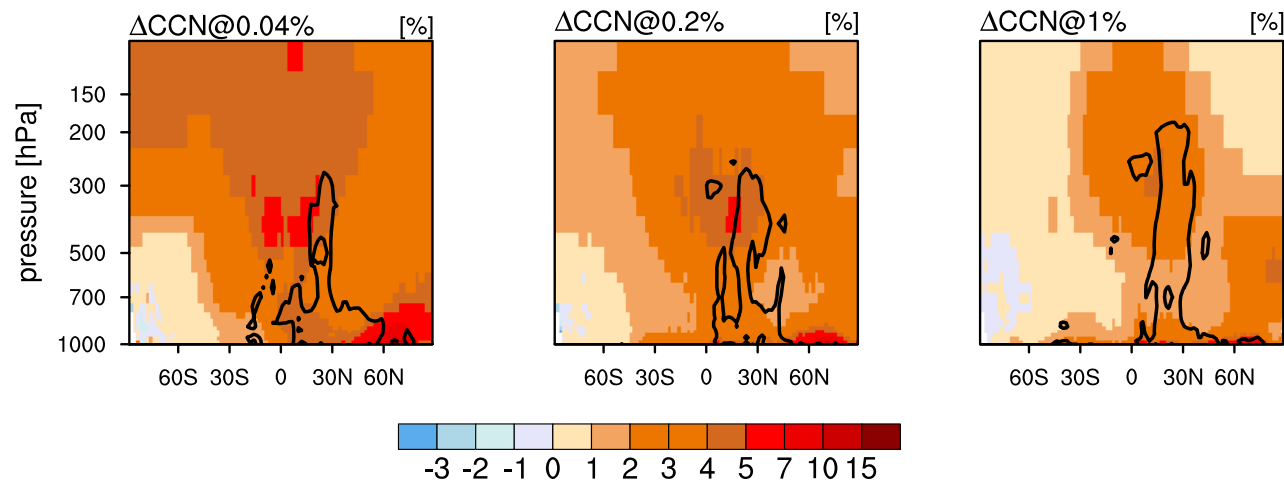

Fig. 5. Ship-emission induced five-year annual mean relative changes in [\%] of the temporally- and zonally averaged cloud condensation nuclei $(\mathrm{CCN})$ concentrations at supersaturations $S=0.04 \%$ (left), $S=0.2 \%$ (middle) and $S=1 \%$ (right) in experiment B compared to experiment CTRL (derived from $\left.\left(\frac{\mathrm{B}-\mathrm{CTRL}}{\mathrm{CTRL}} \cdot 100\right)\right)$. Please note the non-linear contour spacing. The black contour lines enclose areas showing statistical significance at the $90 \%$ level.
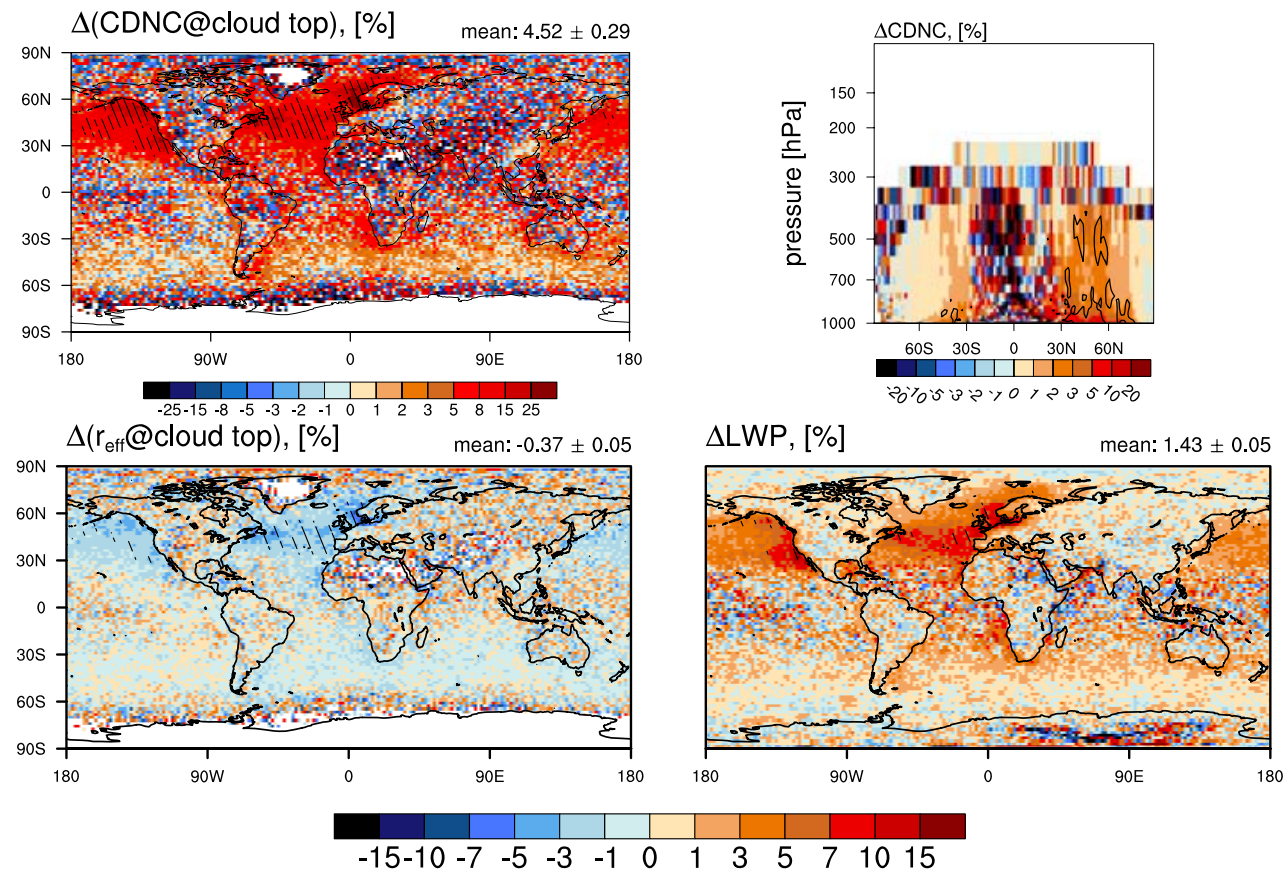

Fig. 6. Ship-emission induced five-year annual mean relative changes in [\%] of micro- and macrophysical cloud properties in experiment B compared to experiment CTRL computed as $\left(\frac{B-C T R L}{C T R L} \cdot 100\right)$ : cloud droplet number concentration (CDNC) at cloud top (top left), CDNC concentrations (top right), cloud droplet effective radius ( $\left.r_{\text {eff }}\right)$ at cloud top (bottom left) and cloud liquid water path (LWP) (bottom right). Please note the non-linear contour spacing. For the global plots, changes in diagonally-patterned areas are statistically significant at the $90 \%$ level. For the zonal-average plot, black contour lines enclose areas showing statistical significance at the $90 \%$ level.

Indeed, we find the LWP to increase over large regions (Fig. 6, bottom right). Zonally averaged, the cloud cover is slightly enhanced in the $\mathrm{NH}$ mid-latitude boundary layer (not shown).

\subsection{Impact on the radiative budget}

For the purpose of this study, we define the AIE at TOA in terms of the "radiative flux perturbation" as given in Lohmann et al. (2010). There, the instantaneous radiation perturbation by the total aerosol loading (with cloud microand macrophysical properties held constant), i.e. the direct total aerosol forcing, as obtained from a double-call of the 

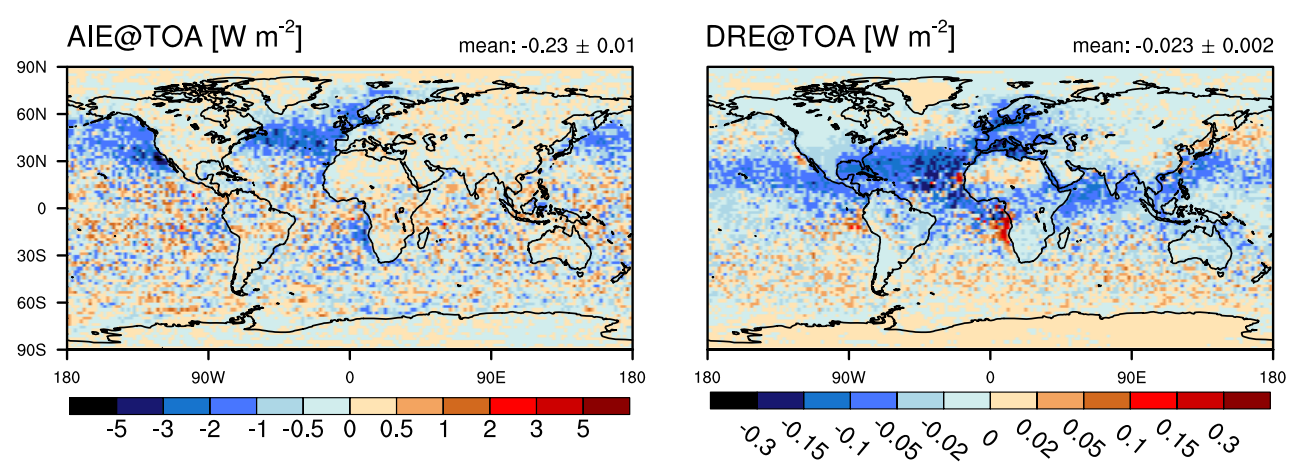

Fig. 7. Ship-emission induced five-year annual mean changes in top-of-atmosphere (TOA) radiation in experiment B with respect to experiment CTRL. The aerosol indirect effect (AIE, left) is computed as the change in "net all-sky radiation - direct aerosol radiative perturbation", the direct radiative effect (DRE, right) is the change in net clear-sky radiation. Please note the non-linear contour spacing. Changes in diagonally-patterned areas are statistically significant at the $90 \%$ level.

ECHAM radiation scheme, is subtracted from the net all-sky radiation at TOA. By evaluating the difference of these fields with respect to the reference simulation, i.e. "experiment CTRL", we thus obtain the changes in the net all-sky radiation as influenced only by changes in cloud micro- and macrophysical properties.

With this definition of the AIE, the results from experiment $\mathrm{B}$ yield a global, five-year mean AIE of shipping emissions at TOA of $-0.23 \pm 0.01 \mathrm{~W} \mathrm{~m}^{-2}$ (see Fig. 7, top left). As expected, the largest contributions come from those areas in which the change in shipping emissions leads to the largest changes in cloud micro- and macrophysical quantities.

We find the direct radiative effect (DRE) of shipping emissions at TOA, as difference between experiments $\mathrm{B}$ and CTRL, to be $-23 \pm 2 \mathrm{~m} \mathrm{~W} \mathrm{~m}^{-2}$ (five-year mean and interannual standard deviation). Interestingly, the DRE is distinctly positive in some parts of the semi-permanent stratocumulus fields off the southern Africa west coast. The reasons for this effect in B can be twofold. Either (1), carbonaceous aerosol from shipping emissions is lofted above the clouds or (2) the absorption of carbonaceous biomass burning aerosol from Africa above the clouds (e.g. Peters et al., 2011a) is increased due to increased internal mixing in the presence of shipping emissions. To investigate this, we compare the results from $\mathrm{B}$ to those of BnoC and BnoBC (not shown) and find that the positive DRE off the coast of Namibia and Angola can be attributed to increased internal mixing of biomass burning aerosol (see also Stier et al., 2006b).

Compared to previous estimates of the DRE from shipping emissions ( -47.5 to $-9.1 \mathrm{~m} \mathrm{~W} \mathrm{~m}^{-2}$, Eyring et al., 2010), our value $\left(-23 \pm 2 \mathrm{~m} \mathrm{~W} \mathrm{~m}^{-2}\right)$ is of comparable magnitude. In previous studies (e.g. Lauer et al., 2007), it is argued that the DRE of shipping emissions is negligible compared to the correspoding AIE. However, here it is evident that the emission of non-absorbing aerosols and aerosol precursors from shipping emissions have implications for the absorption characteristics of pre-existing aerosol and may lead to changes in macrophysical properties of stratocumulus fields (e.g. cloud thickening as described in Wilcox, 2010).

Both the AIE and DRE represent radiative effects in the solar shortwave spectrum. It has been suggested that the aerosol influence on clouds, specifically those stemming from shipping emissions, have the potential to also alter the radiative balance at TOA in the longwave spectral range resulting from cloud deepening (e.g. Christensen and Stephens, 2011). In the results of experiment $\mathrm{B}$, we find negligible changes in the outgoing longwave radiation (OLR) compared to experiment CTRL.

\section{Sensitivity to uncertainties in shipping emissions}

To test the model sensitivity towards assumed emission parameters, like physical and chemical properties of emitted particles as well as the total emission amount, we performed in total seven simulations as described in Sect. 2.4. This section contains a description of the simulated responses to changes in (i) emission parametrisation, (ii) total amount of emissions and (iii) emitted amount of carbonaceous compounds from shipping emissions. The results are shown in Figs. $8-12$ as zonal averages. We supply a summary of globally averaged differences of selected parameters with respect to experiment CTRL in Table 3.

\subsection{Effect of two different emission parametrisations}

We modified the parameterisation of shipping emissions in experiment B in such a way that substantially more soluble particles are emitted compared to the original emission parameterisation as used in experiment A (see Table 1). As we show in the following, the higher number of emitted soluble particles in B leads to substantially different results compared to A with respect to aerosol processing and the subsequent effect on cloud micro- and macrophysical properties. 
Table 3. Globally averaged changes of aerosol- and cloud properties for the experiments described in Sect. 2.4 with respect to experiment CTRL, i.e. "experiment - CTRL". The results for cloud droplet number concentration (CDNC) and cloud droplet effective radius $\left(r_{\text {eff }}\right)$ represent values at cloud top as diagnosed by the model. The values in parantheses represent globally averaged relative changes in $\%$ as $\left(\frac{\mathrm{B}-\mathrm{CTRL}}{\mathrm{CTRL}} \cdot 100\right)$.

\begin{tabular}{|c|c|c|c|c|c|c|c|}
\hline & AOD & AOD FMF & $\begin{array}{c}\mathrm{ADE} \\
{\left[\mathrm{m} \mathrm{W} \mathrm{m}^{-2}\right]}\end{array}$ & $\begin{array}{l}\mathrm{CDNC} \\
{\left[\mathrm{cm}^{-3}\right]}\end{array}$ & $\begin{array}{c}r_{\mathrm{eff}} \\
{[\mu \mathrm{m}]}\end{array}$ & $\begin{array}{c}\mathrm{LWP} \\
{\left[\mathrm{kg} \mathrm{m}^{-2}\right]}\end{array}$ & $\begin{array}{c}\mathrm{AIE} \\
{\left[\mathrm{W} \mathrm{m}^{-2}\right]}\end{array}$ \\
\hline A & $\begin{array}{c}1.9 \mathrm{E}-3 \pm 0.07 \mathrm{E}-3 \\
(1.51 \pm 0.02)\end{array}$ & $\begin{array}{c}4.6 \mathrm{E}-3 \pm 0.1 \mathrm{E}-3 \\
(0.86 \pm 0.03)\end{array}$ & $-23.5 \pm 0.9$ & $\begin{array}{l}0.84 \pm 0.05 \\
(3.12 \pm 0.2)\end{array}$ & $\begin{array}{l}-0.03 \pm 0.003 \\
(-0.07 \pm 0.04)\end{array}$ & $\begin{array}{c}6.6 \mathrm{E}-4 \pm 0.6 \mathrm{E}-4 \\
(0.61 \pm 0.05)\end{array}$ & $-0.07 \pm 0.017$ \\
\hline B & $\begin{array}{c}2.3 \mathrm{E}-3 \pm 0.1 \mathrm{E}-3 \\
(1.87 \pm 0.04)\end{array}$ & $\begin{array}{l}5.4 \mathrm{E}-3 \pm 0.08 \mathrm{E}-3 \\
(1 \pm 0.02)\end{array}$ & $-23 \pm 1.7$ & $\begin{array}{l}1.64 \pm 0.18 \\
(4.5 \pm 0.3)\end{array}$ & $\begin{array}{l}-0.07 \pm 0.006 \\
(-0.37 \pm 0.05)\end{array}$ & $\begin{array}{c}2 \mathrm{E}-3 \pm 0.06 \mathrm{E}-3 \\
(1.43 \pm 0.05)\end{array}$ & $-0.23 \pm 0.008$ \\
\hline Asc & $\begin{array}{c}3 \mathrm{E}-3 \pm 0.07 \mathrm{E}-3 \\
(2.47 \pm 0.04)\end{array}$ & $\begin{array}{c}7.3 \mathrm{E}-3 \pm 0.02 \mathrm{E}-3 \\
(1.36 \pm 0.04)\end{array}$ & $-38 \pm 1.5$ & $\begin{array}{c}1.24 \pm 0.17 \\
(3.65 \pm 0.29)\end{array}$ & $\begin{array}{l}-0.04 \pm 0.009 \\
(-0.15 \pm 0.08)\end{array}$ & $\begin{array}{c}1 \mathrm{E}-3 \pm 0.05 \mathrm{E}-3 \\
(0.94 \pm 0.05)\end{array}$ & $-0.11 \pm 0.02$ \\
\hline Bsc & $\begin{array}{l}3.7 \mathrm{E}-3 \pm 0.13 \mathrm{E}-3 \\
\quad(3 \pm 0.06)\end{array}$ & $\begin{array}{c}8.7 \mathrm{E}-3 \pm 0.15 \mathrm{E}-3 \\
(1.62 \pm 0.05)\end{array}$ & $-37.4 \pm 1.6$ & $\begin{array}{c}2.6 \pm 0.2 \\
(6.13 \pm 0.34)\end{array}$ & $\begin{array}{l}-0.09 \pm 0.005 \\
(-0.58 \pm 0.04)\end{array}$ & $\begin{array}{l}3 \mathrm{E}-3 \pm 0.1 \mathrm{E}-3 \\
\quad(2 \pm 0.07)\end{array}$ & $-0.32 \pm 0.01$ \\
\hline BnoBC & $\begin{array}{c}2.3 \mathrm{E}-3 \pm 0.07 \mathrm{E}-3 \\
(1.86 \pm 0.02)\end{array}$ & $\begin{array}{c}5.3 \mathrm{E}-3 \pm 0.1 \mathrm{E}-3 \\
(1 \pm 0.02)\end{array}$ & $-24.1 \pm 0.7$ & $\begin{array}{c}1.57 \pm 0.08 \\
(4.34 \pm 0.21)\end{array}$ & $\begin{array}{l}-0.06 \pm 0.004 \\
(-0.33 \pm 0.03)\end{array}$ & $\begin{array}{c}2 \mathrm{E}-3 \pm 0.1 \mathrm{E}-3 \\
(1.37 \pm 0.12)\end{array}$ & $-0.21 \pm 0.02$ \\
\hline BnoC & $\begin{array}{c}2.3 \mathrm{E}-3 \pm 0.1 \mathrm{E}-3 \\
(1.83 \pm 0.05)\end{array}$ & $\begin{array}{c}5.1 \mathrm{E}-3 \pm 0.1 \mathrm{E}-3 \\
(0.95 \pm 0.03)\end{array}$ & $-23.9 \pm 1.4$ & $\begin{array}{c}1.8 \pm 0.14 \\
(4.88 \pm 0.3)\end{array}$ & $\begin{array}{l}-0.06 \pm 0.007 \\
(-0.35 \pm 0.06)\end{array}$ & $\begin{array}{c}2.1 \mathrm{E}-3 \pm 0.09 \mathrm{E}-3 \\
(1.41 \pm 0.08)\end{array}$ & $-0.22 \pm 0.02$ \\
\hline
\end{tabular}
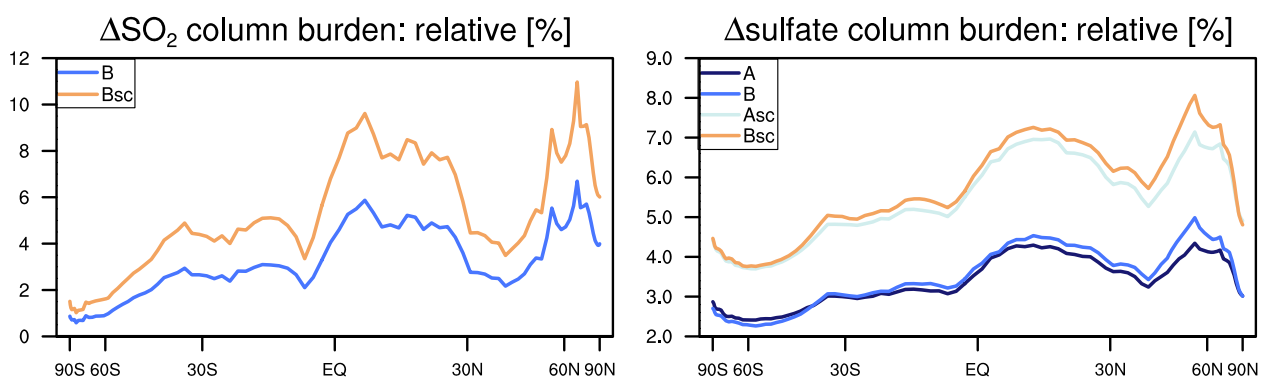

$\Delta \mathrm{BC}$ column burden: relative $[\%]$
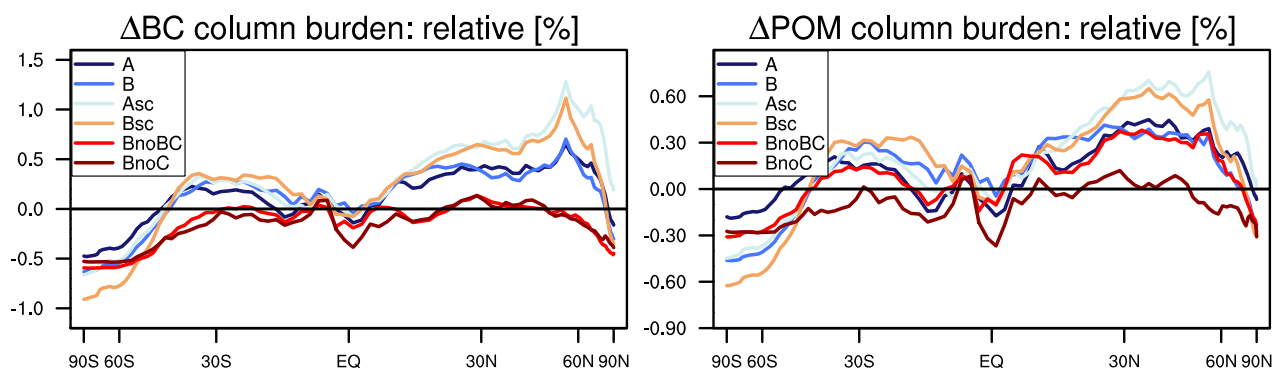

Fig. 8. Ship-emission induced five-year annual zonally averaged relative changes of atmospheric column burdens with respect to CTRL computed as ( $\left.\frac{\text { experiment"-CTRL }}{\text { CTRL }} \cdot 100\right)$ : sulphur dioxide $\left(\mathrm{SO}_{2}\right.$, top left), sulfate (top right), black carbon (BC, bottom left) and particulate organic matter ( $\mathrm{POM}$, bottom right). Relative changes in $\mathrm{SO}_{2}$ column burdens obtained from experiments $\mathrm{A}$, $\mathrm{BnoC}$ and $\mathrm{BnoBC}$ are very similar to B whereas changes in Asc are very similar to those in Bsc. Changes in sulfate column burdens in BnoBC and BnoC are very similar to those obtained from B.

Regarding changes in species column burdens (Fig. 8), carbonaceous species are slightly more abundant in the midlatitudes of both hemispheres in A compared to B. This may be due to regionally reduced lifetimes of carbonaceous particles in B - on a global scale, there is no systematic change in carbonaceous particle lifetimes (with respect to experiment CTRL) detectable (see Table 2). Due to the change in $f_{\mathrm{SO}_{4}}$,
$\mathrm{SO}_{2}$ is less and sulfate is more abundant in A, respectively (see Fig. 8).

Differences in particle number column burdens (Figs. 9 and 10) are most pronounced for the modes KI and AS. For $\mathrm{KI}$ in $\mathrm{A}$, particle numbers increase south of $30^{\circ} \mathrm{S}$ and north of $15^{\circ} \mathrm{N}$ due to the emission of insoluble carbonaceous particles. Between $30^{\circ} \mathrm{S}$ and $15^{\circ} \mathrm{N}$, KI particle numbers are reduced for both experiments $\mathrm{A}$ and $\mathrm{B}$. The most pronounced 

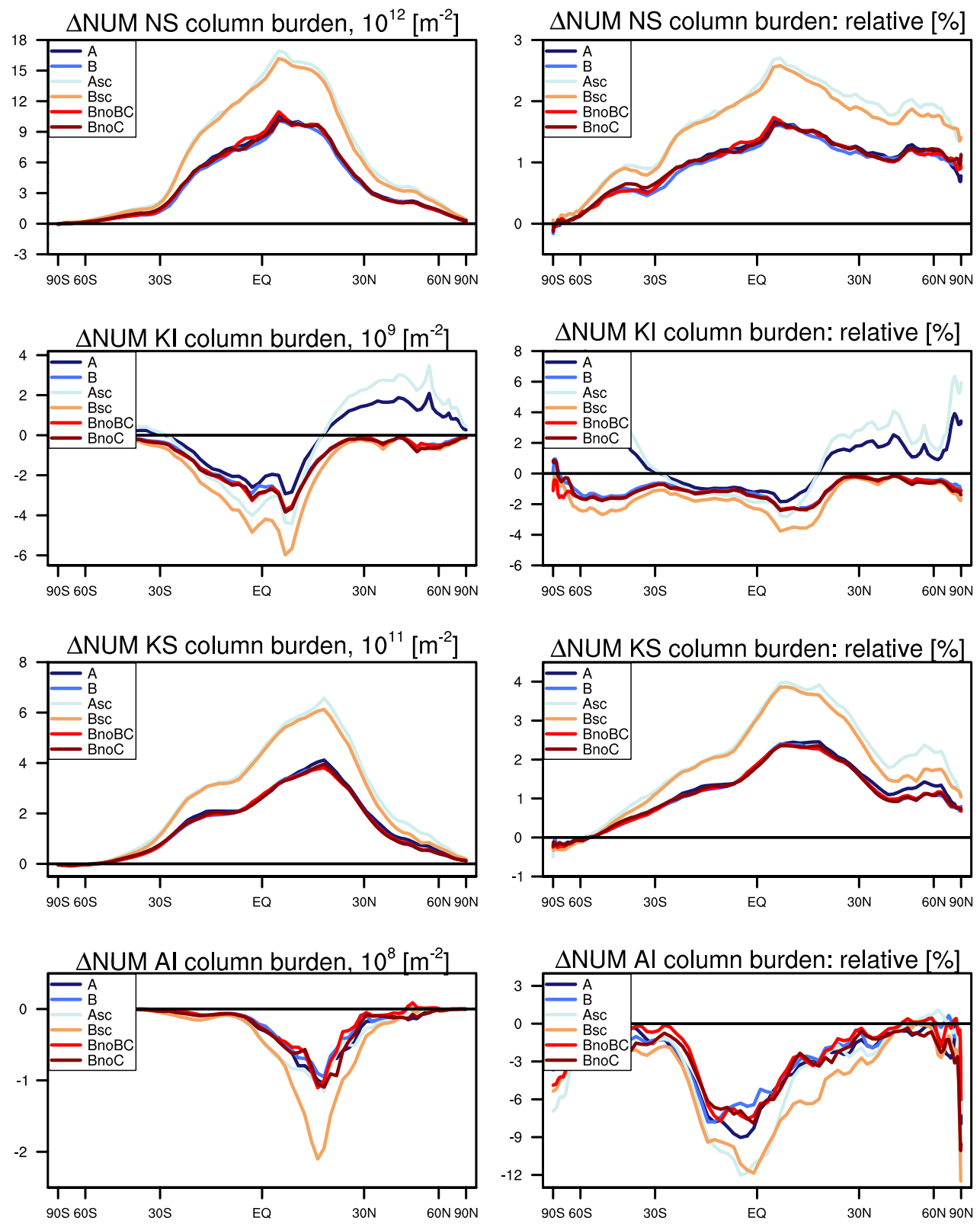

Fig. 9. Ship-emission induced five-year annual zonally averaged absolute- and relative changes of atmospheric column number burdens with respect to CTRL and aerosol mode in ECHAM-HAM: Nucleation mode soluble (NS, top), Aitken mode insoluble (KI, second from top), Aitken mode soluble (KS, second from bottom) and Accumulation mode insoluble (AI, bottom). Relative changes are derived from $\left(\frac{\text { "experiment"-CTRL }}{\text { CTRL }} \cdot 100\right)$.

absolute decrease is simulated over South America, subSahel Africa, and northern Australia (not shown). In these regions, carbonaceous emissions from biomass-burning are partly assigned to KI (Stier et al., 2005) and represent an efficient condensational sink regarding ship-emitted condensable species.

In experiment $\mathrm{A}$ it therefore seems that microphysical ageing of emitted KI particles over main shipping corridors is insufficient for efficient internal mixing and thus particle growth. Boundary layer nucleation is also higher in A compared to B (not shown), but boundary layer KS particle numbers are higher in $\mathrm{B}$, indicating the inefficient microphysical ageing of emitted KI particles in A. The changes in AS column number burdens clearly reflect this (Fig. 10, top row). There, the relative increase obtained from $\mathrm{B}$ is distinctly higher than that of $\mathrm{A}$, especially in the $\mathrm{NH}$ mid-latitudes. Less efficient internal mixing in $\mathrm{A}$ also results in longer particle lifetimes, due to reduced scavenging efficiency, and 

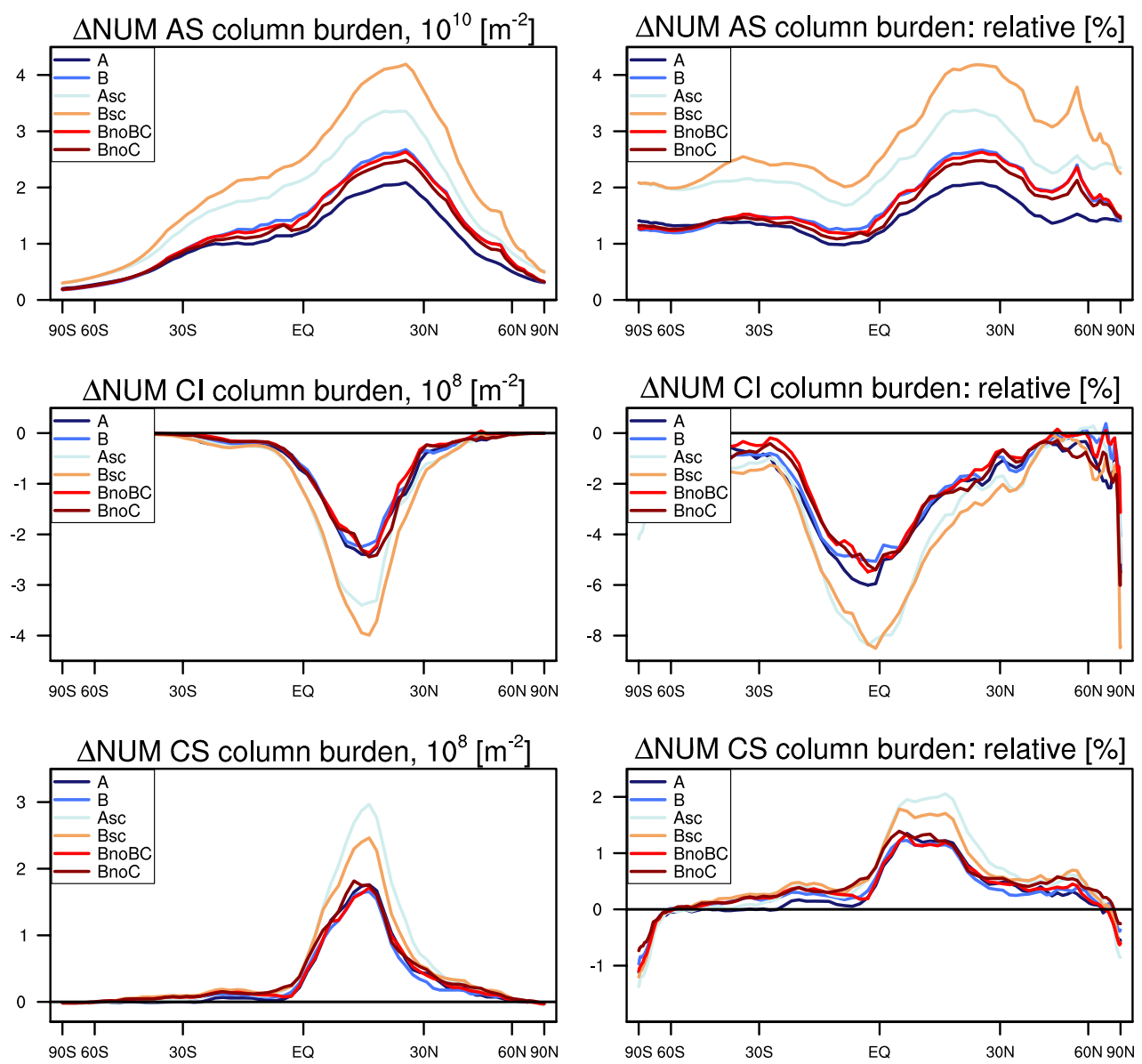

Fig. 10. Ship-emission induced five-year annual zonally averaged absolute- and relative changes of atmospheric column number burdens with respect to CTRL and aerosol mode in ECHAM-HAM: accumulation mode soluble (AS, top), Coarse mode insoluble (CI, middle) and Coarse mode soluble (CS, bottom). Relative changes are derived as $\left(\frac{\text { "experiment"-CTRL }}{\text { CTRL }} \cdot 100\right)$.

subsequent higher total column number burdens compared to B (not shown).

The resulting changes in zonally averaged aerosol optical depth (AOD) and its fine mode fraction (Fig. 11) match the changes in number burdens and are thus larger for $\mathrm{B}$ than for A. So despite the results from A yielding a slightly larger total aerosol number burden, B yields more particles in larger size modes which subsequently leads to higher AOD values. This also holds for the changes in the AOD fine mode fraction because the experimental setup of B leads to substantially more particles in AS. The changes in the AOD of absorption are also higher for $\mathrm{B}$ due to internally mixed $\mathrm{BC}$ particles. The resulting aerosol direct radiative effect (DRE) is however not much different between the two experiments: $-23.5 \pm 0.9 \mathrm{~m} \mathrm{~W} \mathrm{~m}^{-2}$ and $-22.9 \pm 1.7 \mathrm{~m} \mathrm{~W} \mathrm{~m}^{-2}$ for $\mathrm{A}$ and B, respectively (Fig. 11, bottom right).

The relative change in zonally averaged CDNC at cloud top (Fig. 12, top left) is substantially larger in B than A, i.e. about $5 \%$ vs. $2 \%$ at $\mathrm{NH}$ mid-latitudes. Correspondingly, the $r_{\text {eff }}$ decreases by more than $1 \%$ in B versus about $0.25 \%$ in A (Fig. 12, top right). The changes in cloud liquid water path (LWP) also show the same distinct difference pattern. While the LWP increases by almost $4 \%$ over NH midlatitudes in $\mathrm{B}$, this increase amounts to only $<1 \%$ in $\mathrm{A}$ Fig. (12, bottom left).

The globally averaged AIE from B amounts to $-0.22 \pm$ $0.008 \mathrm{~W} \mathrm{~m}^{-2}$ whereas that of $\mathrm{A}$ is simulated at $-0.07 \pm$ $0.017 \mathrm{~W} \mathrm{~m}^{-2}$. For both simulations, the zonally averaged AIE (Fig. 12, bottom right) is largest over the NH midlatitudes, amounting to about -0.7 and $-0.2 \mathrm{~W} \mathrm{~m}^{-2}$ for $\mathrm{B}$ and $\mathrm{A}$, respectively. In experiment $\mathrm{B}$, it is therefore the effect of assigning more and smaller soluble particles for a given amount of emissions (see Table 1) which leads to more than a tripling of the AIE in ECHAM-HAM for the model configuration we used in this study. A similar dependence of shipping emission induced AIEs to the size distribution of emitted particles was found by Righi et al. (2011).

We performed a preliminary investigation to pinpoint the process responsible for most of the increase in radiative forcing. In our study, the increase in the number of emitted 

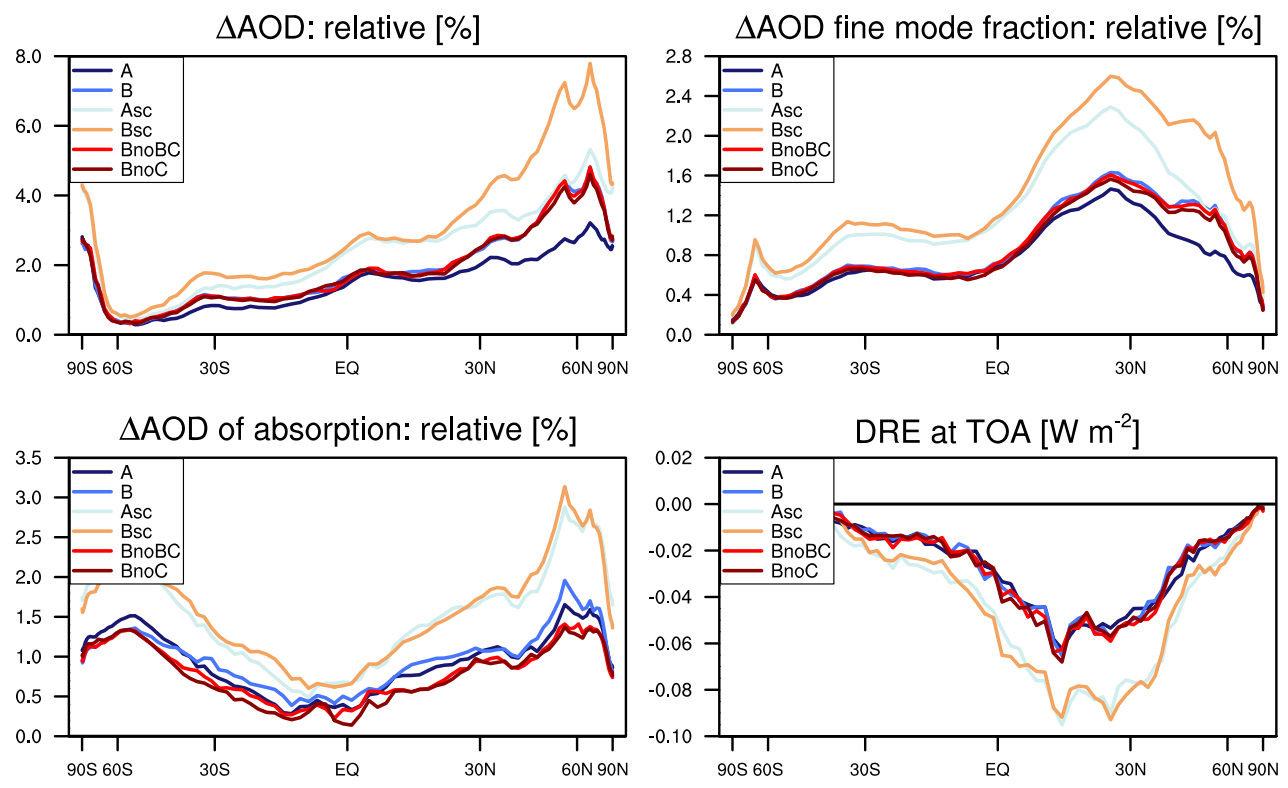

Fig. 11. Ship-emission induced five-year annual zonally averaged relative changes of quantities related to direct aerosol-radiation interaction

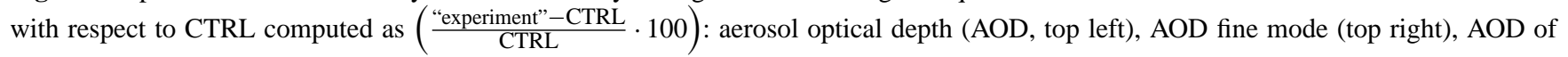
absorption (bottom left). The resulting aerosol direct radiative effect(DRE) at TOA is also shown (bottom right).

soluble particles in experiment B compared to A is caused by three factors: (i) increasing $f_{\mathrm{SO}_{4}}$, (ii) changing the emission size distribution of primary sulfate particles and (iii) assigning carbonaceous emissions to the soluble instead of the insoluble Aitken mode. We find that it is the change in the emission size distribution of primary sulfate particles which makes up for the bulk of the change in AIE. Future measurement campaigns should thus focus on characterising the evolution of the emitted particle size distribution from the scale of the emission plume to the scale of global model resolutions.

\subsection{Effects of changes in the amount of emissions}

Although we illustrated that the AIE of shipping emissions as calculated by an aerosol-climate model such as ECHAM-HAM strongly depends on the chosen emission parametrisation, we investigate a possibly more obvious AIE-determinant in this section: the uncertainty associated with total shipping emissions.

With respect to the results of experiments $\mathrm{A}$ and $\mathrm{B}$, the results obtained from Asc and Bsc (see Sect. 2.4) show the same zonally averaged patterns for all investigated parameters, but with an offset. From experiment Bsc, we obtain an upper estimate of the globally averaged AIE from shipping emissions (i.e. $-0.32 \pm 0.01 \mathrm{~W} \mathrm{~m}^{-2}$ ), which is about half of the largest of previously published estimates of AIEs from shipping emissions $\left(-0.60 \mathrm{~W} \mathrm{~m}^{-2}\right.$ as given in Lauer et al., 2007). However, our results compare well with the highest estimate given in Righi et al. (2011) $\left(-0.40 \mathrm{~W} \mathrm{~m}^{-2}\right)$ who also used higher total annual emissions compared to our study.

In our experiments, the AIE does not scale linearly with the emissions, i.e. an increase of about $40 \%$ versus a $63 \%$ increase in emissions compared to B. The non-linearity also applies to all relevant diagnostics, e.g. species burdens, particle numbers, $\mathrm{CCN}$ concentrations, etc. This is most probably due to saturation effects in the aerosol system (see also Stier et al., 2006a). For Asc, the increase in forcing scales more closely with the increase in emissions $(57 \%$ increase compared to A), indicating lower saturation of the aersol system compared to B.

\subsection{Reduction of carbonaceous emissions}

In the experiments $\mathrm{BnoBC}$ and $\mathrm{BnoC}$, we set the emissions of $\mathrm{BC}$ and $\mathrm{BC}+\mathrm{POM}$ from ships, respectively, to zero to investigate the relevance of primary carbonaceous particle emissions from ships for the calculated aerosol indirect effect. The zonally averaged relative changes of BC column burdens indicate lower values in both experiments than those of the reference experiment CTRL (Fig. 8, bottom left). This is due to increased internal mixing and the subsequently decreased lifetime of already present BC-particles. The same holds for the relative changes of POM column burden in experiment BnoC (Fig. 8, bottom right).

Although the number of emitted particles is surely lower in BnoBC and BnoC compared to B, the effect of shipping emissions on clouds and radiation is nearly the same. Analysis of mode-wise aerosol mass mixing ratios (MMRs) 
$\triangle \mathrm{CDNC}$ at cloud top: relative [\%]

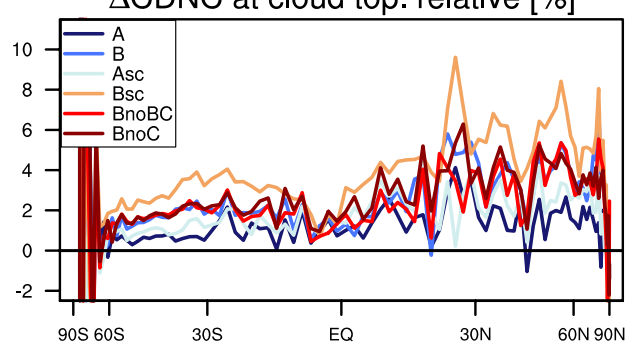

$\Delta$ LWP: relative $[\%]$

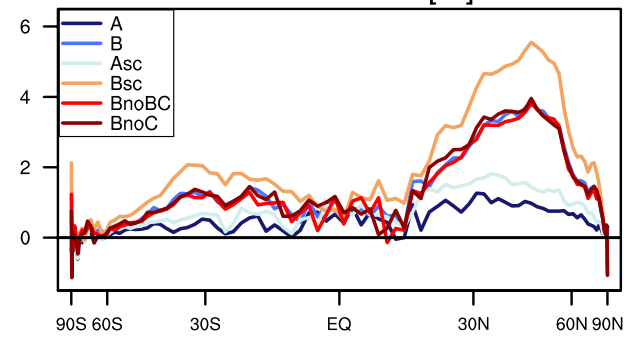

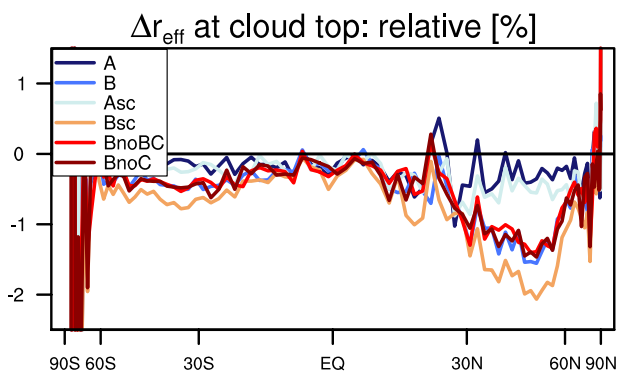

AIE at TOA $\left[\mathrm{W} \mathrm{m}^{-2}\right]$

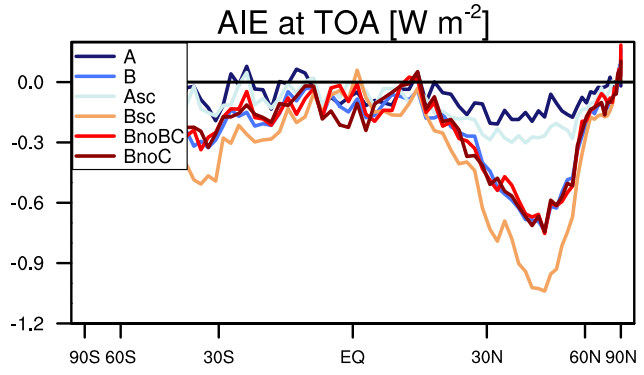

Fig. 12. Ship-emission induced five-year annual zonally averaged relative changes of quantities related to aerosol-cloud interaction with

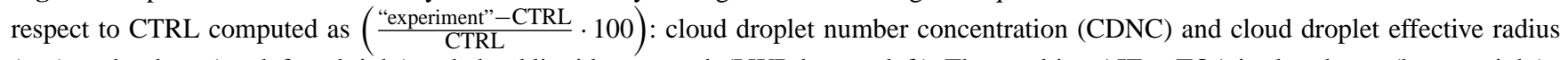
$\left(r_{\text {eff }}\right)$ at cloud top (top left and right) and cloud liquid water path (LWP, bottom left). The resulting AIE at TOA is also shown (bottom right).

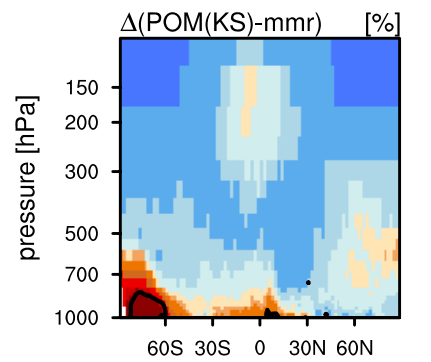

+
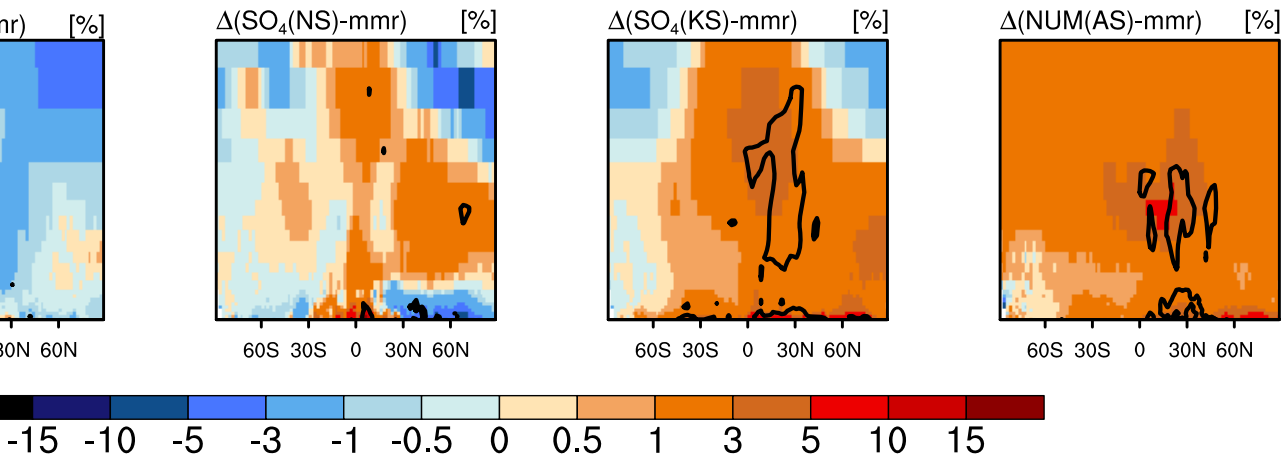

Fig. 13. Ship-emission induced five-year annual zonal mean relative changes in [\%] of (from left to right) POM(KS), sulfate(NS and KS) mass mixing ratios and total number mixing ratio in $\mathrm{AS}$ in experiment $\mathrm{BnoC}$ compared to experiment $\mathrm{B}$ derived from $\left(\frac{\mathrm{BnoC}-\mathrm{B}}{\mathrm{B}} \cdot 100\right)$. Please note the non-linear contour spacing. The black contour lines enclose areas showing statistical significance at the $90 \%$ level.

reveals that changes in the aerosol microphysical state are evident, especially in BnoC. The involved mechanisms nicely illustrate competitive effects between primary particle emission and secondary particle formation. We show zonally and meridionally averaged relative changes of selected aerosol species MMRs in experiment $\mathrm{BnoC}$ compared to $\mathrm{B}$ in Fig. 13. The depicted changes in POM-MMR for KS are also representative for the changes in BC-MMR in KS and show the expected reduction throughout the boundary layer. The model calculates an increase of sulfate particle mass NS and $\mathrm{KS}$, indicating increased particle nucleation in BnoC compared to $\mathrm{B}$. As a result, the total aerosol number mixing ratio in AS (Fig. 13, right), i.e. the highly relevant mode for CCN formation, is about the same in both experiments. Therefore, due to the reduced number of primarily emitted carbonaceous particles, the condensational sink for sulfuric acid is reduced, leaving more ship-emitted $\mathrm{SO}_{2}$ available for new particle formation. Interestingly, the newly formed and grown particles contribute just about as many particles to AS as the primary carbonaceous particles did, leaving the globally averaged aerosol indirect effect largely unchanged (Fig. 12, bottom left). The described effects are smaller in BnoBC and follow the same causality.

In recent literature, several studies have advocated the importance of accounting for carbonaceous particles in the CCN budget (e.g. Pierce et al., 2007; Spracklen et al., 2011) and that not doing so could lead to substantial underestimates of the AIE. Our results partly confirm these studies, 
namely that carbonaceous particles from shipping emissions play an important role in determining the CCN budget. However, we do not find that omitting carbonaceous particle emissions from ships leads to noticeably reduced AIEs due to the compensating effect of increased boundary layer nucleation. This is likely to be a consequence of their predominant emission in pristine environments (low condensational sink). Although our results represent a somewhat extreme scenario, our findings are of particular importance when considering future ship-fuel regulations, as the combustion of higherquality ship fuel leads to less carbonaceous particle emissions compared to the currently used bunker fuels (Lack and Corbett, 2012).

Regarding changes of the DRE, the zonally averaged relative change of the $\mathrm{AOD}$ of absorption is reduced in $\mathrm{BnoBC}$ and $\mathrm{BnoC}$ with respect to $\mathrm{B}$. This combines the effects of both the reduction of carbonaceous emissions from ships and the general decrease of carbonaceous-compound lifetimes. Omitting emissions of BC and POM from ships therefore results in a slightly more negative DRE compared to experiment $\mathrm{B}$ (see Table 3), highlighting the positive forcing component (at TOA) of these species.

\section{Summary and conclusions}

In this study, we used the aerosol climate model ECHAMHAM to quantify the aerosol indirect effect (AIE) from shipping emissions. For this, we used the shipping emissions inventory from Behrens (2006) and designed the experiments to investigate the uncertainty of the derived radiative forcing (RF) associated with the uncertainty in the shipping emissions themselves. For these experiments, ECHAMHAM was nudged with ERA-Interim re-analysis data, sea surface temperatures (SSTs) were prescribed by AMIP data, and the model integrations span the time frame of October 1999-December 2004. The first three months were used as model spin-up and discarded from the analysis.

The sensitivity experiments consisted of three sets of simulations in which the following key uncertainties/questions, with respect to AIEs, were assessed:

1. Uncertainty in the emitted particle-size distribution and -composition.

2. Uncertainty in amount of emissions.

3. The effect of reducing carbonaceous emissions from shipping.

We addressed the first uncertainty by modifying the originally implemented emission parameterisation (AeroCom, Dentener et al., 2006). Compared to that parametrisation, we assigned all particles from shipping emissions to a soluble and/or smaller aerosol mode with a higher fraction of emitted sulfur instantaneously transformed to particulate sulfate. Thus, the modified emission parametrisation leads to the emission of substantially more soluble particles. The modifications to the emission parametrisation were within the observed ranges (see Sect. 2.4). We did not investigate the effect of employing a different geographical distribution of the shipping emissions, such as that presented in Wang et al. (2007) and used in Lamarque et al. (2010), because the effect on the obtained AIE-estimate would most probably be negligible compared to that obtained when using the given geographical emission-distribution of Behrens (2006) (according to the results shown in Lauer et al., 2007).

The second uncertainty arises from the fact that the global annual amount of fuel consumed by ship traffic is still not fully constrained. There do exist relatively low and high estimates of annual fuel consumption, with the emissions inventory we employed in this study (Behrens, 2006) providing an estimate which is on the lower end. Therefore, we scaled the emissions to meet the highest published value (see Sect. 2.4) and therefore framed this emission sensitivity analysis within the range of published uncertainties.

For quantifying the third question, we performed two simulations. In the first one, only black carbon (BC) emissions from shipping were omitted and in the second one, all BCand particulate organic matter (POM) emissions were omitted.

The different model experiments yield substantially different RFs at TOA and we found the strongest estimate of the AIE at TOA from shipping emissions to be $-0.32 \pm$ $0.01 \mathrm{~W} \mathrm{~m}^{-2}$ from the model run performed with the modified emission parametrisation and scaled emissions. This is a factor of two smaller than the upper estimate from Lauer et al. (2007), who also used the ECHAM model, but used slightly different cloud microphysics and coupled it to a different aerosol sub-model. In Lauer et al. (2007), the zonally averaged AIE is much larger in the tropics and subtropics compared to our results (Fig. 13, bottom right), yielding a substantially higher global mean value. The difference in the distribution of the forcing may have its cause in the applied aerosol modules, the representation of tropospheric chemistry or differences in the coupling of the aerosol microphysical to the cloud microphysical parameterisations. It is beyond the scope of this study to delve into the exact differences between the two model versions, but it should be noted that the two employed aerosol sub-models differ in terms of their representation of the aerosol size distribution, treatment of aerosol species and representation of tropospheric chemistry (see AEROCOM phase 1 publications for more detail, e.g. Textor et al., 2006). In addition Lauer et al. (2007) calculated aerosol activation following Abdul-Razzak and Ghan (2000) whereas this was treated following Lin and Leaitch (1997) in our simulations. However, our results compare well with those presented in Righi et al. (2011), who used the same GCM environment as Lauer et al. (2007) but employed a different geographical distribution of shipping emissions.

We found that the emission size distribution matters far more than the amount of total emissions. Even in the case 
of scaled emissions, the experiment with the original emission parametrisation yielded an AIE at TOA of $-0.11 \pm$ $0.02 \mathrm{~W} \mathrm{~m}^{-2}$, showing how the forcing increases by a factor of three when employing the modified emission parametrisation. This also holds for the cases with unscaled emissions, where the experiments employing the original- and modified parametrisation yield an AIE at TOA of $-0.07 \pm$ $0.017 \mathrm{~W} \mathrm{~m}^{-2}$ and $-0.23 \pm 0.008 \mathrm{~W} \mathrm{~m}^{-2}$ respectively.

We recognised that carbonaceous particle emissions from ships play an important role in determining the boundary layer CCN budget. However, omitting carbonaceous aerosol from the shipping emissions proved not to have a substantial impact on the obtained AIE as suggested by studies advocating the importance of accounting for carbonaceous CCN (e.g. Pierce et al., 2007; Spracklen et al., 2011). This is because in our model, omitting carbonaceous particle emissions from ships lead to enhanced boundary-layer new particle formation, which is likely to be a consequence of their predominant emission in pristine environments (low condensational sink), favourable for aerosol nucleation. This compensated for the reduced primary particle emissions, leaving the globally averaged AIE nearly unaltered. This effect may however not appear in regions in which the potential for new particle formation is lower, e.g. already heavily polluted industrial areas.

Generally, we find that the impact of shipping emissions on cloud micro- and macrophysical properties is largest and most statistically significant throughout the shipping corridors covering the North Atlantic- and North Pacific Oceans as well as off the southwestern coast of Africa. The changes in cloud properties over tropical oceans are rather noisy because here, the relatively large variations in macrophysical cloud properties, such as cloud liquid water path/geometrical thickness, dominate the signal even for the five year averages considered here. This is in-line with the conclusions presented in the observations-based study of Peters et al. (2011b) and a more thorough comparison to observations will be performed in future work.

As there exists a considerable inter-model spread regarding total AIEs (e.g. Penner et al., 2006; Quaas et al., 2009), it must be noted that the estimated range of AIEs stemming from shipping emissions crucially depends on the employed GCM model setup, encompassing the used convection, cloud cover and aerosol- and cloud-microphysical parameterisations. Future effort should therefore focus on performing model intercomparison studies of not just total aerosol indirect effects, but also of aerosol indirect effects attributable to a certain economical sector, e.g. shipping emissions.

It must also be investigated what processes on the subgrid scale lead to the substantial reduction of statistically significant changes down the track from changes in emissions to changes in cloud radiative properties. The question then arises whether an ever more realistic treatment of aerosol processes in GCMs eventually leads to them becoming almost irrelevant on a global scale.
Acknowledgements. The authors thank Jeff Pierce and one anonymous reviewer for their constructive feedback which substantially improved the paper as well as Ulrike Niemeier (MPI-M) for reviewing an earlier version of this manuscript. Kai Zhang and Sebastian Rast (MPI-M) assisted with performing the simulations. The shipping emission inventory was provided in the framework of of the European Union FP6 Integrated Project QUANTIFY. The model simulations were performed at the German High Performance Computing Centre for Climate and Earth System Research (Deutsches Klimarechenzentrum, DKRZ). K. Peters was partly funded by the European Union FP6 Integrated Project QUANTIFY, by the European Commission under the EU Seventh Research Framework Programme (grant 218793, MACC) and by the Australian Research Council within the Centre of Excellence on Climate System Science and acknowledges the funding support from the Guest-Exchange program of the International Max Planck Research School on Earth System Modelling (IMPRSESM) for supporting his visit to the University of Oxford. UK. P. Stier was partly supported by the UK NERC AEROS project (NE/G006148/1). The work of J. Quaas was funded by the German Research Foundation (DFG) in an "Emmy Noether" grant.

The service charges for this open access publication have been covered by the Max Planck Society.

Edited by: H. Tost

\section{References}

Abdul-Razzak, H. and Ghan, S.: A parameterization of aerosol activation 2. Multiple aerosol types, J. Geophys. Res., 105, 68376844, doi:10.1029/1999JD901161, 2000.

Agrawal, H., Malloy, Q., Welch, W., Wayne Miller, J., and Cocker III, D.: In-use gaseous and particulate matter emissions from a modern ocean going container vessel, Atmos. Environ., 42, 5504-5510, doi:10.1016/j.atmosenv.2008.02.053, 2008.

Agrawal, H., Welch, W., Henningsen, S., Miller, J., and Cocker III, D.: Emissions from main propulsion engine on container ship at sea, J. Geophys. Res, 115, D23205, doi:10.1029/2009JD013346, 2010.

Albrecht, B. A.: Aerosols, Cloud Microphysics, and Fractional Cloudiness, Science, 245, 1227-1230, 1989.

Ångström, A.: Atmospheric turbidity, global illumination and planetary albedo of the earth, Tellus, 14, 435-450, 1962.

Balkanski, Y., Myhre, G., Gauss, M., Rädel, G., Highwood, E. J., and Shine, K. P.: Direct radiative effect of aerosols emitted by transport: from road, shipping and aviation, Atmos. Chem. Phys., 10, 4477-4489, doi:10.5194/acp-10-4477-2010, 2010.

Behrens, H. L.: Present Traffic and Emissions from Maritime Shipping, in: Deliverable D1.1.2.2 of the EU-IP QUANTIFY (confidential), Det Norske Veritas, http://www.pa.op.dlr.de/quantify/, 2006.

Bond, T.: Can warming particles enter global climate discussions?, Environ. Res. Lett., 2, 045030, doi:10.1088/17489326/2/4/045030, 2007.

Bond, T., Streets, D., Yarber, K., Nelson, S., Woo, J., and Klimont, Z.: A technology-based global inventory of black and organic carbon emissions from combustion, J. Geophys. Res, 109, D14203, doi:10.1029/2003JD003697, 2004. 
Borken-Kleefeld, J., Berntsen, T., and Fuglestvedt, J.: Specific climate impact of passenger and freight transport, Environ. Sci. Technol., 44, 5700-5706, doi:10.1021/es9039693, 2010.

Buhaug, Ø., Corbett, J., Endresen, Ø., Eyring, V., Faber, J., Hanayama, S., Lee, D., Lee, D., Lindstad, H., Markowska, A., Mjelde, A., Nelissen, D., Nilsen, J., Pålsson, C., Winebrake, J., Wu, W.-Q., and Yoshida, K.: Second IMO GHG study 2009, International Maritime Organization (IMO), London, UK, 24, 2009.

Capaldo, K., Corbett, J., Kasibhatla, P., Fischbeck, P., and Pandis, S.: Effects of ship emissions on sulphur cycling and radiative climate forcing over the ocean, Nature, 400, 743-746, 1999.

Christensen, M. and Stephens, G.: Microphysical and macrophysical responses of marine stratocumulus polluted by underlying ships: Evidence of cloud deepening, J. Geophys. Res.-Atmos., 116, D03201, doi:10.1029/2010JD014638, 2011.

Corbett, J. and Koehler, H.: Updated emissions from ocean shipping, J. Geophys. Res, 108, 4650-4664, 2003.

Corbett, J. and Koehler, H.: Considering alternative input parameters in an activity-based ship fuel consumption and emissions model: Reply to comment by Øyvind Endresen et al. on Updated emissions from ocean shipping, J. Geophys. Res., 109, D23303, doi:10.1029/2004JD005030, 2004.

Corbett, J., Fischbeck, P., and Pandis, S.: Global nitrogen and sulfur inventories for oceangoing ships, J. Geophys. Res, 104, 34573470, doi:10.1029/1998JD100040, 1999.

Dalsøren, S. B., Eide, M. S., Endresen, Ø., Mjelde, A., Gravir, G., and Isaksen, I. S. A.: Update on emissions and environmental impacts from the international fleet of ships: the contribution from major ship types and ports, Atmos. Chem. Phys., 9, 2171-2194, doi:10.5194/acp-9-2171-2009, 2009.

Dentener, F., Kinne, S., Bond, T., Boucher, O., Cofala, J., Generoso, S., Ginoux, P., Gong, S., Hoelzemann, J. J., Ito, A., Marelli, L., Penner, J. E., Putaud, J.-P., Textor, C., Schulz, M., van der Werf, G. R., and Wilson, J.: Emissions of primary aerosol and precursor gases in the years 2000 and 1750 prescribed data-sets for AeroCom, Atmos. Chem. Phys., 6, 4321-4344, doi:10.5194/acp-64321-2006, 2006.

Devasthale, A., Krüger, O., and Grassl, H.: Change in Cloud-Top Temperatures Over Europe, IEEE Geosci. Remote S., 2, 333336, doi:10.1109/LGRS.2005.851736, 2005.

Devasthale, A., Krüger, O., and Grassl, H.: Impact of ship emissions on cloud properties over coastal areas, Geophys. Res. Lett., 33, L02811, doi:10.1029/2005GL024470, 2006.

Endresen, Ø., Sørgård, E., Sundet, J., Dalsøren, S., Isaksen, I., Berglen, T., and Gravir, G.: Emission from international sea transportation and environmental impact, J. Geophys. Res., 108, 4560, doi:10.1029/2002JD002898, 2003.

Endresen, Ø., Sørgård, E., Bakke, J., and Isaksen, I.: Substantiation of a lower estimate for the bunker inventory: Comment on Updated emissions from ocean shipping by James J. Corbett and Horst W. Koehler, J. Geophys. Res., 109, D23302, doi:10.1029/2004JD004853, 2004.

Eyring, V., Köhler, H., Lauer, A., and Lemper, B.: Emissions from international shipping: 2. Impact of future technologies on scenarios until 2050, J. Geophys. Res., 110, D17306, doi:10.1029/2004JD005620, 2005a.

Eyring, V., Köhler, H., Van Aardenne, J., and Lauer, A.: Emissions from international shipping: 1 . The last 50 years, J. Geophys.
Res., 110, D17305, doi:10.1029/2004JD005619, 2005b.

Eyring, V., Isaksen, I. S. A., Berntsen, T., Collins, W. J., Corbett, J. J., Endresen, O., Grainger, R. G., Moldanova, J., Schlager, H., and Stevenson, D. S.: Transport impacts on atmosphere and climate: Shipping, Atmos. Environ., 44, 4735-4771, doi:10.1016/j.atmosenv.2009.04.059, 2010.

Feichter, J., Kjellström, E., Rodhe, H., Dentener, F., Lelieveldi, J., and Roelofs, G.: Simulation of the tropospheric sulfur cycle in a global climate model, Atmos. Environ., 30, 1693-1707, 1996.

Forster, P., Ramaswamy, V., Artaxo, P., Berntsen, T., Betts, R., Fahey, D. W., Haywood, J., Lean, J., Lowe, D. C., Myhre, G., Nganga, J., Prinn, R., Raga, G., Schulz, M., and Van Dorland, R.: Changes in Atmospheric Constituents and in Radiative Forcing, in: Climate Change 2007: The Physical Science Basis. Contribution of Working Group I to the Fourth Assessment Report of the Intergovernmental Panel on Climate Change, edited by Solomon, S., Qin, D., Manning, M., Chen, Z., Marquis, M., Averyt, K. B., Tignor, M., and Miller, H. L., Cambridge University Press, Cambridge, United Kingdom and New York, NY, USA, 2007.

Franke, K., Eyring, V., Sander, R., Hendricks, J., Lauer, A., and Sausen, R.: Toward effective emissions of ships in global models, Meteorol. Z., 17, 117-129, doi:10.1127/0941-2948/2008/0277, 2008.

Fuglestvedt, J., Berntsen, T., Eyring, V., Isaksen, I., Lee, D. S., and Sausen, R.: Shipping Emissions: From Cooling to Warming of Climate - and Reducing Impacts on Health, Environ. Sci. Technol., 43, 9057-9062, doi:10.1021/es901944r, 2009.

Gehlot, S. and Quaas, J.: Convection-climate feedbacks in the ECHAM5 general circulation model: Evaluation of cirrus cloud life cycles with ISCCP satellite data from a Lagrangian trajectory perspective, J. Climate, doi:10.1175/JCLI-D-11-00345.1, in press, 2012.

Guelle, W., Schulz, M., Balkanski, Y., and Dentener, F.: Influence of the source formulation on modeling the atmospheric global distribution of sea salt aerosol, J. Geophys. Res., 106, 2750927524, 2001.

Horowitz, L., Walters, S., Mauzerall, D., Emmons, L., Rasch, P., Granier, C., Tie, X., Lamarque, J., Schultz, M., Tyndall, G., Orlando, J., and Brasseur, G.: A global simulation of tropospheric ozone and related tracers: Description and evaluation of MOZART, version 2, J. Geophys. Res, 108, 4784, doi:10.1029/2002JD002853, 2003.

Huszar, P., Cariolle, D., Paoli, R., Halenka, T., Belda, M., Schlager, H., Miksovsky, J., and Pisoft, P.: Modeling the regional impact of ship emissions on $\mathrm{NO}_{\mathrm{x}}$ and ozone levels over the Eastern Atlantic and Western Europe using ship plume parameterization, Atmos. Chem. Phys., 10, 6645-6660, doi:10.5194/acp-10-66452010, 2010.

IMO: Regulations for the prevention of air pollution from ships and $\mathrm{NO}_{\mathrm{X}}$ technical code, ANNEX IV of MARPOL 73/78, Tech. rep., London, 1998.

Kazil, J. and Lovejoy, E. R.: A semi-analytical method for calculating rates of new sulfate aerosol formation from the gas phase, Atmos. Chem. Phys., 7, 3447-3459, doi:10.5194/acp-7-3447-2007, 2007.

Kazil, J., Stier, P., Zhang, K., Quaas, J., Kinne, S., O’Donnell, D., Rast, S., Esch, M., Ferrachat, S., Lohmann, U., and Feichter, J.: Aerosol nucleation and its role for clouds and Earth's radiative forcing in the aerosol-climate model ECHAM5-HAM, 
Atmos. Chem. Phys., 10, 10733-10752, doi:10.5194/acp-1010733-2010, 2010

Kettle, A. and Andreae, M.: Flux of dimethylsulfide from the oceans- A comparison of updated data sets and flux models, J. Geophys. Res., 105, 793-808, 2000.

Khairoutdinov, M. and Kogan, Y.: A new cloud physics parameterization in a large-eddy simulation model of marine stratocumulus, Mon. Weather Rev., 128, 229-243, 2000.

Kinne, S., Schulz, M., Textor, C., Guibert, S., Balkanski, Y., Bauer, S. E., Berntsen, T., Berglen, T. F., Boucher, O., Chin, M., Collins, W., Dentener, F., Diehl, T., Easter, R., Feichter, J., Fillmore, D., Ghan, S., Ginoux, P., Gong, S., Grini, A., Hendricks, J., Herzog, M., Horowitz, L., Isaksen, I., Iversen, T., Kirkevåg, A., Kloster, S., Koch, D., Kristjansson, J. E., Krol, M., Lauer, A., Lamarque, J. F., Lesins, G., Liu, X., Lohmann, U., Montanaro, V., Myhre, G., Penner, J., Pitari, G., Reddy, S., Seland, O., Stier, P., Takemura, T., and Tie, X.: An AeroCom initial assessment - optical properties in aerosol component modules of global models, Atmos. Chem. Phys., 6, 1815-1834, doi:10.5194/acp-6-1815-2006, 2006.

Kireeva, E., Popovicheva, O., Persiantseva, N., Timofeyev, M., and Shonija, N.: Fractionation analysis of transport engine-generated soot particles with respect to hygroscopicity, J. Atmos. Chem., 64, 129-147, doi:10.1007/s10874-010-9173-y, 2010.

Koch, D. and Del Genio, A. D.: Black carbon semi-direct effects on cloud cover: review and synthesis, Atmos. Chem. Phys., 10, 7685-7696, doi:10.5194/acp-10-7685-2010, 2010.

Koren, I., Kaufman, Y., Rosenfeld, D., Remer, L., and Rudich, Y.: Aerosol invigoration and restructuring of Atlantic convective clouds, Geophys. Res. Lett., 32, L14828, doi:10.1029/2005GL023187, 2005.

Kulmala, M., Lehtinen, K. E. J., and Laaksonen, A.: Cluster activation theory as an explanation of the linear dependence between formation rate of $3 \mathrm{~nm}$ particles and sulphuric acid concentration, Atmos. Chem. Phys., 6, 787-793, doi:10.5194/acp-6-787-2006, 2006.

Kyoto Protocol: Kyoto Protocol to the United Nations Framework Convention on Climate Change, United Nations Publications: Geneva, Switzerland, 1997.

Lack, D. A. and Corbett, J. J.: Black carbon from ships: a review of the effects of ship speed, fuel quality and exhaust gas scrubbing, Atmos. Chem. Phys., 12, 3985-4000, doi:10.5194/acp-12-39852012, 2012.

Lack, D. A., Corbett, J. J., Onasch, T., Lerner, B., Massoli, P., Quinn, P. K., Bates, T. S., Covert, D. S., Coffman, D., Sierau, B., Herndon, S., Allan, J., Baynard, T., Lovejoy, E., Ravishankara, A. R., and Williams, E.: Particulate emissions from commercial shipping: Chemical, physical, and optical properties, J. Geophys. Res.-Atmos., 114, D00F04, doi:10.1029/2008JD011300, 2009.

Lamarque, J.-F., Bond, T. C., Eyring, V., Granier, C., Heil, A., Klimont, Z., Lee, D., Liousse, C., Mieville, A., Owen, B., Schultz, M. G., Shindell, D., Smith, S. J., Stehfest, E., Van Aardenne, J., Cooper, O. R., Kainuma, M., Mahowald, N., McConnell, J. R., Naik, V., Riahi, K., and van Vuuren, D. P.: Historical (1850-2000) gridded anthropogenic and biomass burning emissions of reactive gases and aerosols: methodology and application, Atmos. Chem. Phys., 10, 7017-7039, doi:10.5194/acp10-7017-2010, 2010.
Lauer, A., Eyring, V., Hendricks, J., Jöckel, P., and Lohmann, U.: Global model simulations of the impact of ocean-going ships on aerosols, clouds, and the radiation budget, Atmos. Chem. Phys., 7, 5061-5079, doi:10.5194/acp-7-5061-2007, 2007.

Lauer, A., Eyring, V., Corbett, J., Wang, C., and Winebrake, J.: Assessment of Near-Future Policy Instruments for Oceangoing Shipping: Impact on Atmospheric Aerosol Burdens and the Earth's Radiation Budget, Environ. Sci. Technol., 43, 55925598, doi:10.1021/es900922h, 2009.

Lin, H. and Leaitch, W.: Development of an in-cloud aerosol activation parameterization for climate modelling, in: Proceedings of the WMO Workshop on Measurement of Cloud Properties for Forecasts of Weather, Air Quality and Climate, Mexico City, 328-335, 1997.

Lin, S. and Rood, R.: Multidimensional flux-form semi-Lagrangian transport schemes, Mon. Weather Rev., 124, 2046-2070, 1996.

Lohmann, U., Stier, P., Hoose, C., Ferrachat, S., Kloster, S., Roeckner, E., and Zhang, J.: Cloud microphysics and aerosol indirect effects in the global climate model ECHAM5-HAM, Atmos. Chem. Phys., 7, 3425-3446, doi:10.5194/acp-7-3425-2007, 2007.

Lohmann, U., Rotstayn, L., Storelvmo, T., Jones, A., Menon, S., Quaas, J., Ekman, A. M. L., Koch, D., and Ruedy, R.: Total aerosol effect: radiative forcing or radiative flux perturbation?, Atmos. Chem. Phys., 10, 3235-3246, doi:10.5194/acp-10-32352010, 2010.

Myhre, G.: Consistency between satellite-derived and modeled estimates of the direct aerosol effect, Science, 325, 187, doi:10.1126/science.1174461, 2009.

Nam, C. C.-W.: Using CALIPSO and CloudSat satellite retrievals to evaluate low-level cloud parameterizations in ECHAM5 for cloud-climate feedbacks implications, in: Berichte zur Erdsystemforschung, 88, 132 pp., ISSN: 1614-1199, Max-PlanckInstitut für Meteorologie, 2011.

Nam, C. C. W. and Quaas, J.: Evaluation of clouds and precipitation in the ECHAM5 general circulation model using CALIPSO and CloudSat satellite data, J. Climate, doi:10.1175/JCLI-D-1100347.1, in press, 2012.

Nordeng, T.: Extended versions of the convective parametrization scheme at ECMWF and their impact on the mean and transient activity of the model in the tropics, in: Tech. Memo., 206, European Centre for Medium-Range Weather Forecasts, Reading, UK, 1994.

Olivier, J. G. J., Van Aardenne, J. A., Dentener, F. J., Pagliari, V., Ganzeveld, L. N., and Peters, J. A. H. W.: Recent trends in global greenhouse gas emissions:regional trends 1970-2000 and spatial distributionof key sources in 2000, Environ. Sci., 2, 81-99, doi:10.1080/15693430500400345, 2005.

Paoli, R., Cariolle, D., and Sausen, R.: Review of effective emissions modeling and computation, Geosci. Model Dev., 4, 643667, doi:10.5194/gmd-4-643-2011, 2011.

Penner, J. E., Quaas, J., Storelvmo, T., Takemura, T., Boucher, O., Guo, H., Kirkevåg, A., Kristjánsson, J. E., and Seland, Ø.: Model intercomparison of indirect aerosol effects, Atmos. Chem. Phys., 6, 3391-3405, doi:10.5194/acp-6-3391-2006, 2006.

Peters, K., Quaas, J., and Bellouin, N.: Effects of absorbing aerosols in cloudy skies: a satellite study over the Atlantic Ocean, Atmos. Chem. Phys., 11, 1393-1404, doi:10.5194/acp-11-13932011, 2011a. 
Peters, K., Quaas, J., and Graß1, H.: A search for large-scale effects of ship emissions on clouds and radiation in satellite data, J. Geophys. Res.-Atmos., 116, D24205, doi:10.1029/2011JD016531, 2011 b.

Petzold, A., Hasselbach, J., Lauer, P., Baumann, R., Franke, K., Gurk, C., Schlager, H., and Weingartner, E.: Experimental studies on particle emissions from cruising ship, their characteristic properties, transformation and atmospheric lifetime in the marine boundary layer, Atmos. Chem. Phys., 8, 2387-2403, doi:10.5194/acp-8-2387-2008, 2008.

Pierce, J. R. and Adams, P. J.: Uncertainty in global CCN concentrations from uncertain aerosol nucleation and primary emission rates, Atmos. Chem. Phys., 9, 1339-1356, doi:10.5194/acp-91339-2009, 2009.

Pierce, J. R., Chen, K., and Adams, P. J.: Contribution of primary carbonaceous aerosol to cloud condensation nuclei: processes and uncertainties evaluated with a global aerosol microphysics model, Atmos. Chem. Phys., 7, 5447-5466, doi:10.5194/acp-75447-2007, 2007.

Quaas, J.: Evaluating the "critical relative humidity" as a measure of subgrid-scale variability of humidity in general circulation model cloud cover parameterizations using satellite data, J. Gephys. Res., 117, D09208, doi:10.1029/2012JD017495, 2012.

Quaas, J., Ming, Y., Menon, S., Takemura, T., Wang, M., Penner, J. E., Gettelman, A., Lohmann, U., Bellouin, N., Boucher, O., Sayer, A. M., Thomas, G. E., McComiskey, A., Feingold, G., Hoose, C., Kristjánsson, J. E., Liu, X., Balkanski, Y., Donner, L. J., Ginoux, P. A., Stier, P., Grandey, B., Feichter, J., Sednev, I., Bauer, S. E., Koch, D., Grainger, R. G., Kirkevåg, A., Iversen, T., Seland, Ø., Easter, R., Ghan, S. J., Rasch, P. J., Morrison, H., Lamarque, J.-F., Iacono, M. J., Kinne, S., and Schulz, M.: Aerosol indirect effects - general circulation model intercomparison and evaluation with satellite data, Atmos. Chem. Phys., 9, 8697-8717, doi:10.5194/acp-9-8697-2009, 2009.

Righi, M., Klinger, C., Eyring, V., Hendricks, J., Lauer, A., and Petzold, A.: Climate Impact of Biofuels in Shipping: Global Model Studies of the Aerosol Indirect Effect, Environ. Sci. Technol., 45, 3519-3525, doi:10.1021/es1036157, 2011.

Sandu, I., Stevens, B., and Pincus, R.: On the transitions in marine boundary layer cloudiness, Atmos. Chem. Phys., 10, 2377-2391, doi:10.5194/acp-10-2377-2010, 2010.

Schreier, M., Mannstein, H., Eyring, V., and Bovensmann, H.: Global ship track distribution and radiative forcing from 1 year of AATSR data, Geophys. Res. Lett., 34, L17814, doi:10.1029/2007GL030664, 2007.

Simmons, A., Uppala, S., Dee, D., and Kobayashi, S.: ERA-Interim: New ECMWF reanalysis products from 1989 onwards, ECMWF Newsletter, 110, 25-35, 2007.

Small, J., Chuang, P., Feingold, G., and Jiang, H.: Can aerosol decrease cloud lifetime?, Geophys. Res. Lett., 36, L16806, doi:10.1029/2009GL038888, 2009.

Spracklen, D. V., Carslaw, K. S., Pöschl, U., Rap, A., and Forster, P. M.: Global cloud condensation nuclei influenced by carbonaceous combustion aerosol, Atmos. Chem. Phys., 11, 9067-9087, doi:10.5194/acp-11-9067-2011, 2011.

Stevens, B. and Feingold, G.: Untangling aerosol effects on clouds and precipitation in a buffered system, Nature, 461, 607-613, doi:10.1038/nature08281, 2009.
Stevens, R. G., Pierce, J. R., Brock, C. A., Reed, M. K., Crawford, J. H., Holloway, J. S., Ryerson, T. B., Huey, L. G., and Nowak, J. B.: Nucleation and growth of sulfate aerosol in coal-fired power plant plumes: sensitivity to background aerosol and meteorology, Atmos. Chem. Phys., 12, 189-206, doi:10.5194/acp12-189-2012, 2012.

Stier, P., Feichter, J., Kinne, S., Kloster, S., Vignati, E., Wilson, J., Ganzeveld, L., Tegen, I., Werner, M., Balkanski, Y., Schulz, M., Boucher, O., Minikin, A., and Petzold, A.: The aerosol-climate model ECHAM5-HAM, Atmos. Chem. Phys., 5, 1125-1156, doi:10.5194/acp-5-1125-2005, 2005.

Stier, P., Feichter, J., Kloster, S., Vignati, E., and Wilson, J.: Emission-induced nonlinearities in the global aerosol system: Results from the ECHAM5-HAM aerosol-climate model, J. Climate, 19, 3845-3862, 2006a.

Stier, P., Seinfeld, J. H., Kinne, S., Feichter, J., and Boucher, O.: Impact of nonabsorbing anthropogenic aerosols on clearsky atmospheric absorption, J. Geophys. Res., 111, D18201, doi:10.1029/2006JD007147, 2006b.

Sundqvist, H., Berge, E., and Kristjansson, J.: Condensation and cloud parameterization studies with a mesoscale numerical weather prediction model, Mon. Weather Rev., 117, 1641-1657, 1989.

Taylor, K., Williamson, D., and Zwiers, F.: The sea surface temperature and sea-ice concentration boundary conditions for AMIP II simulations, PCMDI Rep, 60, 28, 2000.

Tegen, I., Harrison, S., Kohfeld, K., Prentice, I., Coe, M., and Heimann, M.: Impact of vegetation and preferential source areas on global dust aerosol: Results from a model study, J. Geophys. Res, 107, 4576, doi:10.1029/2001JD000963, 2002.

Textor, C., Schulz, M., Guibert, S., Kinne, S., Balkanski, Y., Bauer, S., Berntsen, T., Berglen, T., Boucher, O., Chin, M., Dentener, F., Diehl, T., Easter, R., Feichter, H., Fillmore, D., Ghan, S., Ginoux, P., Gong, S., Grini, A., Hendricks, J., Horowitz, L., Huang, P., Isaksen, I., Iversen, I., Kloster, S., Koch, D., Kirkevåg, A., Kristjansson, J. E., Krol, M., Lauer, A., Lamarque, J. F., Liu, X., Montanaro, V., Myhre, G., Penner, J., Pitari, G., Reddy, S., Seland, $\varnothing$., Stier, P., Takemura, T., and Tie, X.: Analysis and quantification of the diversities of aerosol life cycles within AeroCom, Atmos. Chem. Phys., 6, 1777-1813, doi:10.5194/acp-6-1777-2006, 2006.

Tiedtke, M.: A comprehensive mass flux scheme for cumulus parameterization in large- scale models, Mon. Weather Rev., 117, 1779-1800, 1989.

Tompkins, A.: A prognostic parameterization for the subgrid-scale variability of water vapor and clouds in large-scale models and its use to diagnose cloud cover, J. Atmos. Sci., 59, 1917-1942, 2002.

Twomey, S.: Pollution and the planetary albedo, Atmos. Environ., 8, 1251-1256, 1974.

Vignati, E., Wilson, J., and Stier, P.: M7: An efficient size-resolved aerosol microphysics module for large-scale aerosol transport models, J. Geophys. Res, 109, D22202, doi:10.1029/2003JD004485, 2004.

Wang, C., Corbett, J., and Firestone, J.: Improving spatial representation of global ship emissions inventories, Environ. Sci. Technol, 42, 193-199, doi:10.1021/es0700799, 2007.

Wang, H. and Feingold, G.: Modeling Mesoscale Cellular Structures and Drizzle in Marine Stratocumulus. Part II: The Mi- 
crophysics and Dynamics of the Boundary Region between Open and Closed Cells, J. Atmos. Sci., 66, 3257-3275, doi:10.1175/2009JAS3120.1, 2009.

Wilcox, E. M.: Stratocumulus cloud thickening beneath layers of absorbing smoke aerosol, Atmos. Chem. Phys., 10, 1176911777, doi:10.5194/acp-10-11769-2010, 2010.
Zhang, K., O’Donnell, D., Kazil, J., Stier, P., Kinne, S., Lohmann, U., Ferrachat, S., Croft, B., Quaas, J., Wan, H., Rast, S., and Feichter, J.: The global aerosol-climate model ECHAMHAM, version 2: sensitivity to improvements in process representations, Atmos. Chem. Phys. Discuss., 12, 7545-7615, doi:10.5194/acpd-12-7545-2012, 2012. 